\title{
Research on Carrying Capacity of T-Shaped Stiffened Concrete-Filled Steel Tubular Columns Subjected to Eccentrically Compressive Load
}

\author{
Yuanlong Yang $\mathbb{D}^{1,2}$ Xinchen Han, ${ }^{2}$ Bo Nan $\mathbb{D}^{3},{ }^{3}$ and Xin Tang ${ }^{2}$ \\ ${ }^{1}$ Key Lab of Structures Dynamic Behavior and Control, Harbin Institute of Technology, Ministry of Education, \\ Harbin 150090, China \\ ${ }^{2}$ Key Laboratory of New Technology for Construction of Cities in Mountain Area, Chongqing University, Ministry of Education, \\ Chongqing 400045, China \\ ${ }^{3}$ College of Water Conservancy, Shenyang Agricultural University, Shenyang 110866, China
}

Correspondence should be addressed to Bo Nan; nanbo@syau.edu.cn

Received 28 September 2020; Revised 14 January 2021; Accepted 4 February 2021; Published 19 February 2021

Academic Editor: Michael Yam

Copyright (c) 2021 Yuanlong Yang et al. This is an open access article distributed under the Creative Commons Attribution License, which permits unrestricted use, distribution, and reproduction in any medium, provided the original work is properly cited.

\begin{abstract}
In this paper, in order to further study the mechanical behavior of T-shaped stiffened concrete-filled steel tubular (CFST) columns, numerical programs of eccentrically compressive T-shaped stiffened CFST columns were developed to calculate moment $M-\phi$ curvature curves of cross section and column. The calculated curves with the numerical programs agree well with the experimental results. A parametric analysis was carried out to calculate $M-N$ correlation curves of cross section and column to investigate influence of concrete strength $f_{\mathrm{ck}}$, steel yielding strength $f_{\mathrm{y}}$, steel tube thickness $t$, slenderness ratio $\lambda$, and loading angle $\theta$. On the basis of parametric analysis, simplified resistance models of T-shaped CFST section and column were proposed and verified by the numerical analysis results. The simplified resistance models are reliable to predict the mechanical behavior for engineering application.
\end{abstract}

\section{Introduction}

The columns in traditional frame structures, with extended corners to indoor space, normally have larger cross-sectional depths than those of adjacent infilled walls, leading to reduction of usable utilization area and disturbance to indoor environment. Recently, special-shaped columns, as an improved architectural approach, have been increasingly introduced into residential and official buildings. Smooth jointing of special-shaped column and adjacent infilled wall guarantees the efficiency of indoor space and availability to place furniture, which is shown in Figure 1.

Systematic research and extensive engineering practice are mainly on the reinforced concrete special-shaped column. An early study focused on the static behavior of T-shaped and L-shaped columns, subjected to axial compressive load and biaxial eccentrically compressive load. Numerical investigations of RC special-shaped columns were undertaken to computerize the analysis procedure for the purpose of providing design aids for structural engineers [1-6]. Many efficient and accurate methods for solving the bearing capacity were proposed, which promoted the development of special-shaped column structure $[7,8]$. To comply with the develop of housing industry in China, a further experimental and theoretical study was carried extensively concentrating on seismic behaviors for RC special-shaped columns in structural systems, directly for engineering promotions and applications $[9,10]$. However, with respect to applicable building height and seismic fortification intensity, traditional special-shaped reinforced concrete (RC) columns have strict limitations in seismic behavior. 


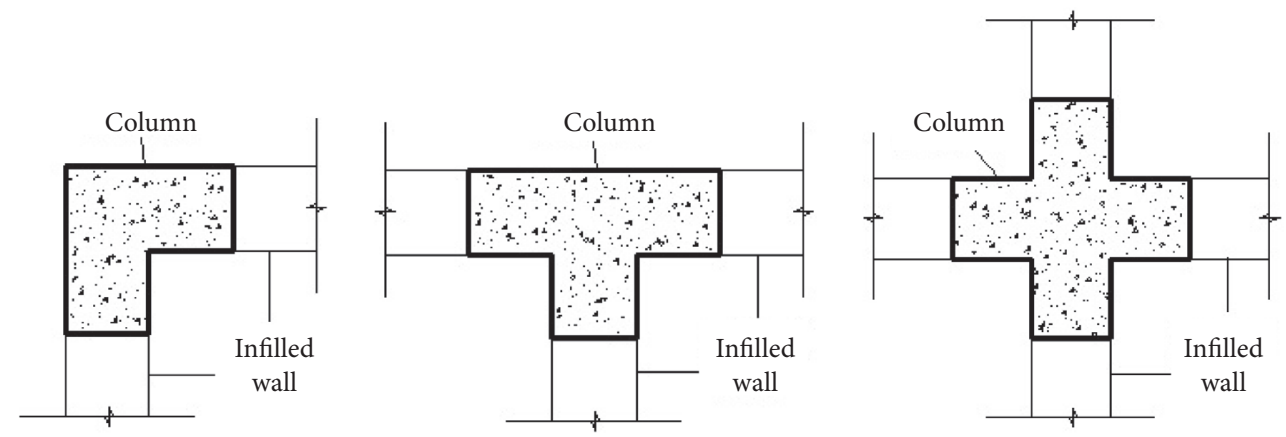

FIgURE 1: Joints in frame structure with special-shaped columns.

In order to promote further generalization and application of special-shaped columns, a series of experimental studies on seismic behavior of T-shaped and L-shaped concrete-filled steel tubular (CFST) columns under constant axial compression and cyclic lateral load were carried out to investigate the effects of different parameters such as axial compression ratio, thickness of steel tube, concrete strength, inner stiffener, and loading scheme [11-16]. The deformation of steel tube at concave corner was almost completely restrained by the vertical stiffener, which acted as the composite dowel connector at the concave corner [17-19]. Besides, extensive researches focused on postponing buckling of steel tubes, and some stiffeners were employed in special-shaped CFST columns. Bar stiffeners were introduced in static and pseudostatic experiments to postpone the premature tube's local buckling and improve constraint effect for concrete [20-23]. Pulled binding bars were adopted at possible plastic hinge locations in the specialshaped CFST columns subjected to concentric and eccentric loads to study their static behavior $[24,25]$. Tensile bars were proposed in the T-shaped CFST columns to postpone local buckling of the tube and increase constraint effect for concrete $[26,27]$. The above experimental results showed that, due to the increase in constraint effect for concrete provided by stiffened steel tubes, special-shaped CFST columns behave advantages on the strength, ductility, and seismic behavior over special-shaped RC columns [28, 29].

The research of T-shaped stiffened CFST columns mentioned above, nevertheless, is inadequate for engineering application, and systematic research should be complemented. In this paper, numerical programs of eccentrically compressive T-shaped stiffened CFST section and column are developed to analyze the influence of different parameters. Based on numerical analysis, simplified resistance models of eccentrically compressive T-shaped CFST section and column are proposed, respectively, to predict the mechanical behavior.

\section{Numerical Program}

2.1. Numerical Programs of Eccentrically Compressive T-Shaped CFST Section and Column. With regard to the eccentrically compressive column, fiber-based model is employed in the following to carry out numerical analysis of the T-shaped CFST cross section and column. Hypothesis of half sine wave was introduced to approximate deformation of the column subjected to eccentrically compressive load. The internal axial force and bending moment are calculated on the weakest cross section at midspan. An iteration process is needed in seeking equilibration of internal and external forces. Due to material nonlinearity, geometric nonlinearity, and cross-sectional nonsymmetry, seeking equilibration needs considering impact of torsional deformation.

The numerical analysis program adopts the following hypotheses: (1) during loading process, the cross section always remains plane, and no relative slip among steel tube, reinforcement, and concrete is taken into consideration; (2) in the analysis of simply supported member, the deformation of longitudinal axis is hypothesized as half sine wave; (3) take no account of the concrete tensile strength and consider concrete quitting work as soon as tensile strain emerges; (4) take no account of the shear deformation of columns.

\subsection{Flow Chart of Numerical Program of T-Shaped CFST} Section Subjected to Eccentrically Compressive Load. The cross-sectional element division and position of vertical load are illustrated in Figure 2. The coordinate origin is located at the centroid of the cross section. The coordinates of axial load $N_{\text {ext }}$ are $e_{x}$ and $e_{y}$. The direction angle $\theta$ of eccentricity is clockwise from positive $x$-axis.

Numerical analysis of the eccentrically compressive behavior of T-shaped concrete-filled steel tubular section is carried out in the following, with the flow chart of numerical program being depicted in Figure 3 .

\subsection{Flow Chart of Numerical Program of T-Shaped CFST} Column Subjected to Eccentrically Compressive Load. A spatial loading diagram of the T-shaped CFST column is shown in Figure 4 . The length of the column is $L$ and the column ends are hinged. It is assumed that the column deforms laterally into a half sine wave. The midspan deflection is denoted by $U_{m}$. The eccentricity of the axial load $N_{\text {ext }}$ is $e$. In the $x y$ plane, the direction angle $\theta$ of eccentricity is clockwise from positive $x$-axis.

Numerical analysis of the eccentrically compressive behavior of T-shaped CFST column is carried out in the following, with the flow chart of numerical program being depicted in Figure 5. 


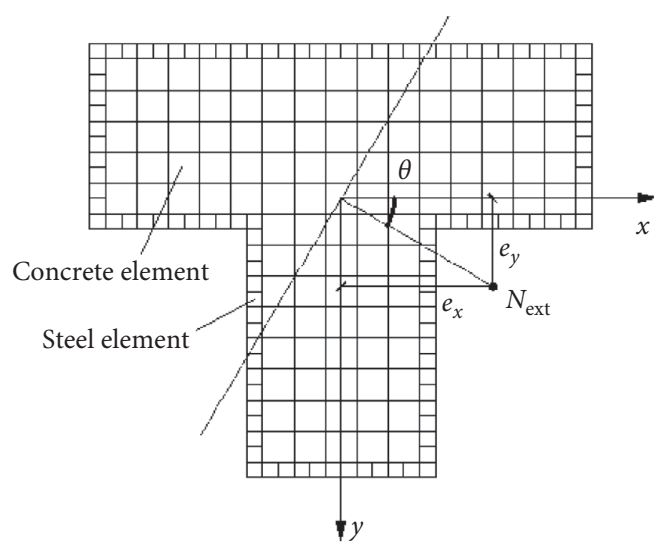

FIGURE 2: Element division of cross section and axial load position.

2.4. Comparison of Numerical Results and Test Results. The numerical analysis program is used to simulate the structural behavior of stiffened T-shaped CFST specimens subjected to eccentrically compressive loads. Axial load next-midspan deflection Um relation curves are calculated to be compared with test results of specimens TE5 and TE6 [26]. To further verify the accuracy of the program, we compared another two specimens B20-180 and B40-180 [30]. It can be seen that good agreement in stiffness, peak resistance, and ductility guarantees the accuracy of the numerical program (Figure 6). The numerical program can be employed to predict mechanical behavior of stiffened T-shaped CFST specimens.

\section{Parametric Analysis}

The influences of concrete strength $f_{\mathrm{ck}}$, steel yielding strength $f_{\mathrm{y}}$, steel tube thickness $t$, slenderness ratio $\lambda$, and loading angle $\theta$ on eccentrically compressive behaviors of cross section and column are mainly investigated in parametric analysis. The cross-sectional dimensions of the columns employ the test data [26]. The basic parameters are as follows: concrete strength $f_{\text {ck }}=26.8 \mathrm{MPa}$, steel yielding strength $f_{\mathrm{y}}=235 \mathrm{MPa}$, steel tube thickness $t=2 \mathrm{~mm}$, axial length $L=1500 \mathrm{~mm}$, slenderness ratio $\lambda=20$, axial compression ratio $n_{0}=0.4$, and eccentricity $e=100 \mathrm{~mm}$. The stiffener is welded in the same way with that in the test [26].

\subsection{Parametric Analysis of Eccentrically Compressive Behavior of T-Shaped CFST Section}

3.1.1. Cross-Sectional M- $\phi$ Relation Curves. Figure 7 shows the influence of the axial compression ratio on cross-sectional $M-\phi$ relation curves. It can be seen that there is no significant decline of resistance in the $M-\phi$ relation curves in the case of forward loading and 45-degree angle loading. With the increase of axial compression ratio $n$, the elastic stiffness decreases gradually, and the peak resistance increases first and then decreases. This is because when the axial compression ratio $n$ is relatively small, concrete in the tension zone of cross section will crack earlier to reduce the resistance; when the axial compression ratio $n$ is relatively large, concrete will be compressed to failure, and steel tube will buckle, which reduces the resistance.

3.1.2. Cross-Sectional $N-M$ and $N / N_{0}-M / M_{0}$ Resistance Correlation Curves. The axial force $N$ - moment $M$ resistance correlation curves of the T-shaped CFST cross section are calculated with the numerical program. Accordingly, the normalized $N / N_{0}-M / M_{0}$ resistance correlation curves are obtained to get rid of the influences of material amount and material strength. $N_{0}$ is axial resistance of the cross section, and $M_{0}$ is the bending resistance of the cross section.

The parametric analysis is carried out to calculate $N-M$ correlation curves of cross section to investigate influence of concrete strength $f_{\mathrm{ck}}$, steel yielding strength $f_{\mathrm{y}}$, steel tube thickness $t$, and loading angle $\theta$, which are shown in Figures 8-11.

Figure 8 shows the influence of concrete strength $f_{\text {ck }}$ on cross-sectional $N-M$ and $N / N_{0}-M / M_{0}$ resistance correlation curves in forward loading. It can be seen that concrete strength $f_{\text {ck }}$ has obvious influence on the resistance correlation curves. With the increase of the concrete strength $f_{\mathrm{ck}}$, the area surrounded by the resistance correlation curve increases, which means an increase in the resistance. For the same concrete strength $f_{\mathrm{ck}}$, the bending resistance $M$ increases first and then decreases with the increase in the axial force $N$. For the normalized $N / N_{0}-M / M_{0}$ resistance correlation curves, with the increase in the concrete strength $f_{\mathrm{ck}}$, the proportion of concrete resistance in the total resistance increases, and the inflection point of the resistance correlation curve is more significant. While the resistance of concrete is relatively low, the proportion of steel behavior is larger, and the inflection point is relatively insignificant.

Figures 9 and 10 show the influence of steel yielding strength $f_{\mathrm{y}}$ and steel tube thickness $t$ on cross-sectional $N-M$ and $N / N_{0}-M / M_{0}$ resistance correlation curves in forward loading. It can be seen that the steel yielding strength $f_{\mathrm{y}}$ and steel tube thickness $t$ have obvious influence on the resistance correlation curves. With the increase of the steel yielding strength $f_{\mathrm{y}}$ and steel tube thickness $t$, the area surrounded by the resistance correlation curve increases, which means an increase in resistance. For the same steel yielding strength $f_{\mathrm{y}}$ and steel tube thickness $t$, the bending resistance $M$ increases first and then decreases with an increase in the axial force $N$. For the normalized $N / N_{0}-M / M_{0}$ resistance correlation curves, with the increase in steel yielding strength $f_{\mathrm{y}}$ and steel tube thickness $t$, the proportion of steel resistance in the total resistance increases, and the inflection point of the resistance correlation curve is insignificant. While the resistance of steel is relatively low, the proportion of concrete behavior is larger, and the inflection point is relatively significant.

Figure 11 shows the influence of loading angle $\theta$ on cross-sectional $N-M$ and $N / N_{0}-M / M_{0}$ resistance correlation curves. The loading angle $\theta$ varies from $-90^{\circ}$ to $90^{\circ}$, divided into positive angle loading and negative angle loading. For the T-section shown in Figure 2, $-90^{\circ}$ angle loading refers to the force state (compressive region in the flange and tensile region in the web), $90^{\circ}$ angle loading refers to the force state 


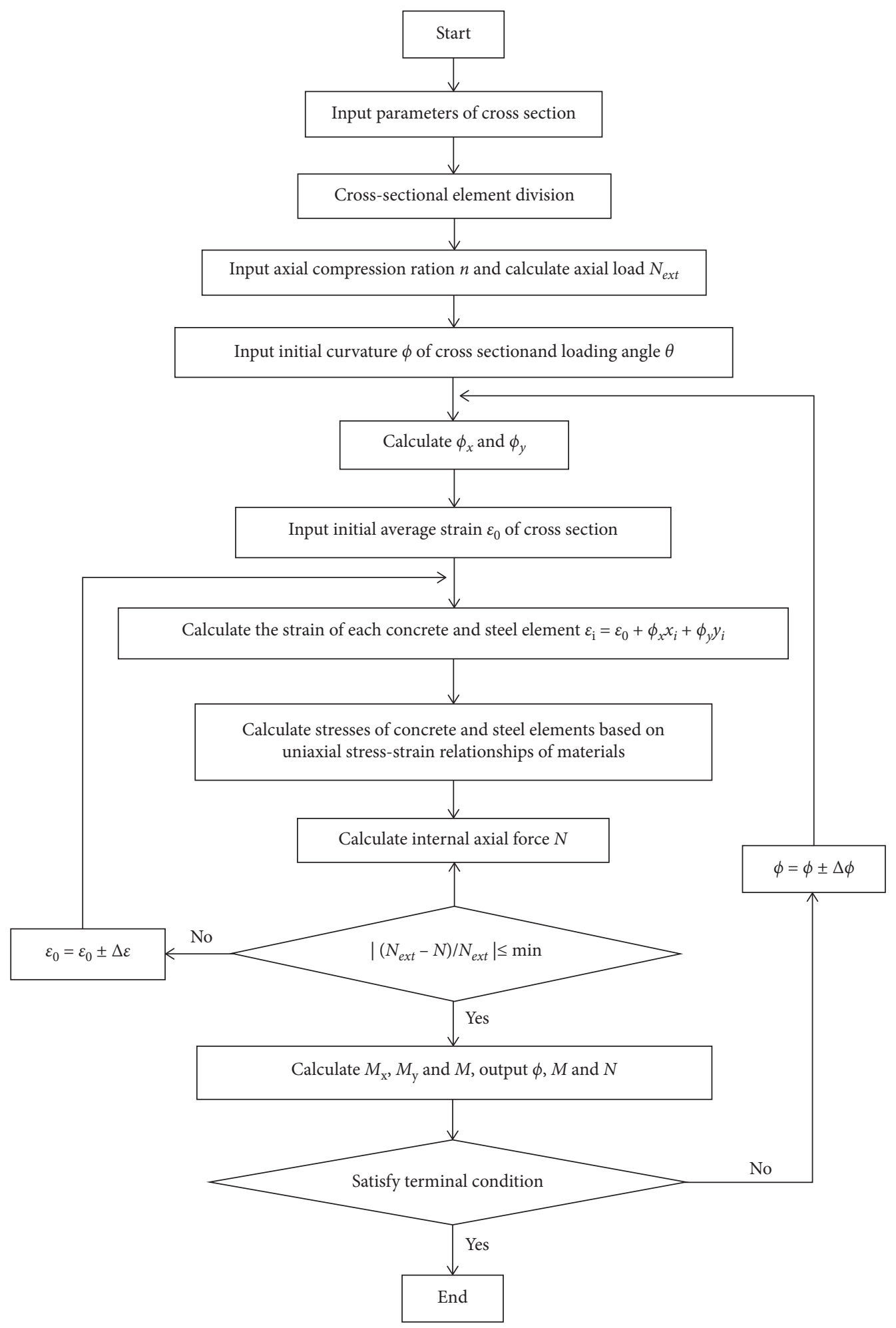

FIGURE 3: Flow chart of numerical program of T-shaped CFST section.

(compressive region in the web and tensile region in the flange), and $0^{\circ}$ angle loading refers to the force state (bending around $Y$-axis). The axial resistance $N_{0}$ of the cross section is constant, and both the pure bending resistance $M_{0}$ and the area surrounded by the resistance correlation curve change greatly with the change of loading angle $\theta$. This is related to the axial compression ratio and the T-shaped section size. When the loading angle $\theta$, the vertical force $N$, and the bending moment $M$ are just to make steel yielding strength $f_{\mathrm{y}}$ and concrete strength $f_{\mathrm{ck}}$ of the cross section play a maximum role at the same time, the cross section has a large resistance, and the area surrounded by the envelope is 


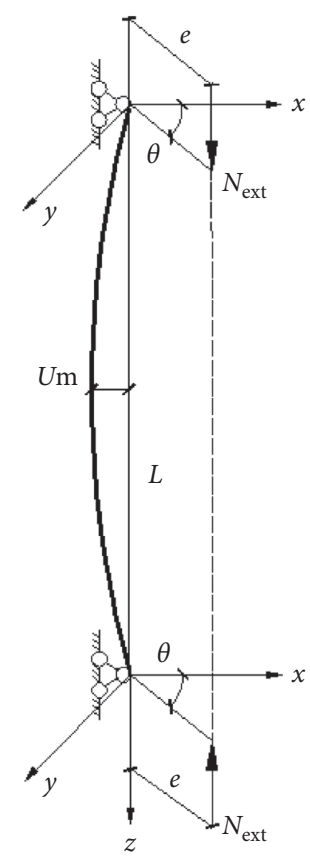

FIGURE 4: Loading diagram of eccentrically compressive column.

largest. It can be seen that when the loading angle $\theta$ varies from 0 to $90^{\circ}$, the inflection point of the resistance correlation curve is most significant from 30 to $45^{\circ}$; when the loading angle $\theta$ varies from 0 to $-90^{\circ}$, the inflection point is most significant at $-90^{\circ}$.

\subsection{Parametric Analysis of Eccentrically Compressive Behavior of T-Shaped CFST Column}

3.2.1. Component-Based $M-\phi$ Relation Curves. Figure 12 shows the influence of the axial compression ratio $n$ on cross-sectional $M-\phi$ relation curves in forward loading. It can be seen that, with the increase of the axial compression ratio $n$, the elastic stiffness of $M-\phi$ relation curves with the slenderness ratio of 20 decreases gradually, and the peak resistance increases first and then decreases. When the slenderness ratio is 100 , with the increase of axial compression ratio $n$, the elastic stiffness and the peak resistance are decreased. This is because when the column is slenderer, the cross-sectional height is smaller than the midspan horizontal displacement, and the second-order effect of eccentrically compressive load is larger, so that the column is mainly subjected to bending failure under any axial compression ratio $n$. That is, concrete in the tension zone of cross section is out of work after cracked, and the resistance is mainly provided by the steel tube. The larger the axial compression ratio $n$ is, the more significant the adverse effect of the second-order effect will be, and the lower the resistance of component will be. The resistance and ductility of the component with a slenderness ratio of 20 are better than those with a slenderness ratio of 100. This is because if the adverse effect of the second- order effect of the axial force is larger, the behavior will be worse.

\subsubsection{Component-Based $N-M$ and $N / N_{0}-M / M_{0}$ Resistance} Correlation Curves. The parametric analysis is carried out to calculate $N-M$ correlation curves of cross section to investigate influence of concrete strength $f_{\mathrm{ck}}$, steel yielding strength $f_{\mathrm{y}}$, steel tube thickness $t$, slenderness ratio $\lambda$, and loading angle $\theta$, which are shown in Figures 13-17.

Figure 13 shows the influence of concrete strength $f_{\mathrm{ck}}$ on component $N-M$ and $N / N_{0}-M / M_{0}$ resistance correlation curves with a slenderness ratio of 20 in forward loading. It can be seen that the concrete strength $f_{\text {ck }}$ has an obvious influence on the component-based resistance correlation curves. With the increase in the concrete strength $f_{\text {ck }}$, the area surrounded by the resistance correlation curve increases, which means an increase in resistance. For the same concrete strength $f_{\mathrm{ck}}$, the bending resistance $M$ increases first and then decreases with the increase in axial force $N$. With the increase in concrete strength $f_{\mathrm{ck}}$, the inflection point of the resistance correlation curve is more significant.

Figures 14 and 15 show the influence of steel yielding strength $f_{\mathrm{y}}$ and steel tube thickness $t$ on component-based $N$ $M$ and $N / N_{0}-M / M_{0}$ resistance correlation curves with a slenderness ratio of 20 in forward loading. It can be seen that the steel yielding strength $f_{\mathrm{y}}$ and steel tube thickness $t$ have an obvious influence on the component-based resistance correlation curves. With the increase of the steel yielding strength $f_{\mathrm{y}}$ and steel tube thickness $t$, the area surrounded by the resistance correlation curve increases, which means the increase of resistance. For the same steel yielding strength $f_{\mathrm{y}}$ and steel tube thickness $t$, the bending resistance $M$ increases first and then decreases with the increase in axial force $N$. With the decrease in steel yielding strength $f_{\mathrm{y}}$ and steel tube thickness $t$, the inflection point of the resistance correlation curve is more significant.

Figure 16 shows the influence of slenderness ratio $\lambda$ on component-based $N-M$ and $N / N_{0}-M / M_{0}$ resistance correlation curves in forward loading. For the different slenderness ratios of $6.7,13.4,20,26.8,33.5,40,60$, and 100 are corresponding to the column lengths $500 \mathrm{~mm}, 1000 \mathrm{~mm}, 1500 \mathrm{~mm}$, $2000 \mathrm{~mm}, 2500 \mathrm{~mm}, 3000 \mathrm{~mm}, 4500 \mathrm{~mm}$, and $7500 \mathrm{~mm}$, respectively. It can be seen that, with the increase of slenderness ratio $\lambda$, the resistance decreases, and the inflection point of the resistance correlation curve gradually disappears, so that the curve approaches the straight line gradually.

Figure 17 shows the influence of loading angle $\theta$ on component-based $N-M$ and $N / N_{0}-M / M_{0}$ resistance correlation curves with a slenderness ratio of 20 . The loading angle $\theta$ varies from $-90^{\circ}$ to $90^{\circ}$, divided into positive angle loading and negative angle loading. For the same loading angle $\theta$, the bending resistance $M$ increases first and then decreases with the increase in axial force $N$. The resistance correlation curve is related to the axial compression ratio $n$ and the T-shaped section size. When the loading angle $\theta$, the vertical force $N$, and the bending moment $M$ are just to make 


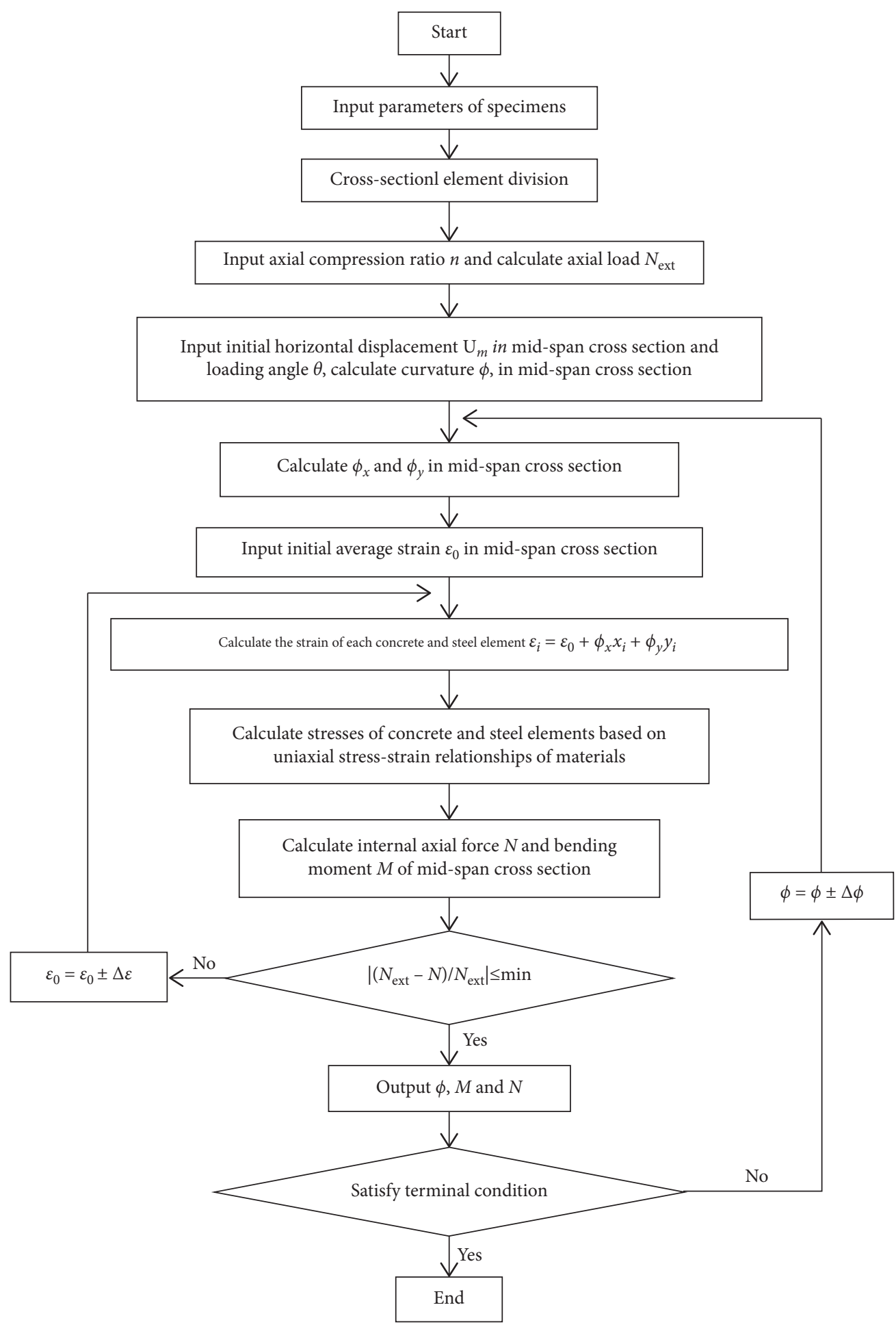

FIGURE 5: Flow chart of numerical program of T-shaped CFST column.

steel yielding strength $f_{\mathrm{y}}$ and concrete strength $f_{\mathrm{ck}}$ of the cross section play a maximum role at the same time, the column has large resistance, and the area surrounded by the envelope is largest. It can be seen that when the loading angle $\theta$ varies from 0 to $90^{\circ}$, the inflection point of the resistance correlation curve is most significant from 30 to $45^{\circ}$; when the loading angle $\theta$ varies from 0 to $-90^{\circ}$, the inflection point is most significant at $-90^{\circ}$.

\section{Simplified Resistance Model}

\subsection{Simplified Model of Cross-Sectional Resistance}

\subsubsection{Basic Hypotheses}

(1) Response superposition of axial load and bending moment is adopted. 


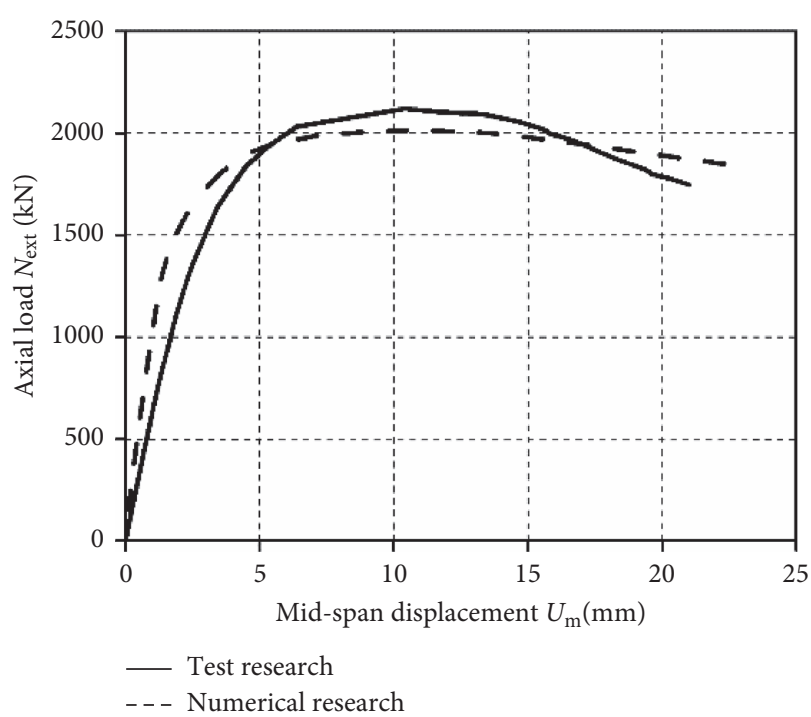

(a)

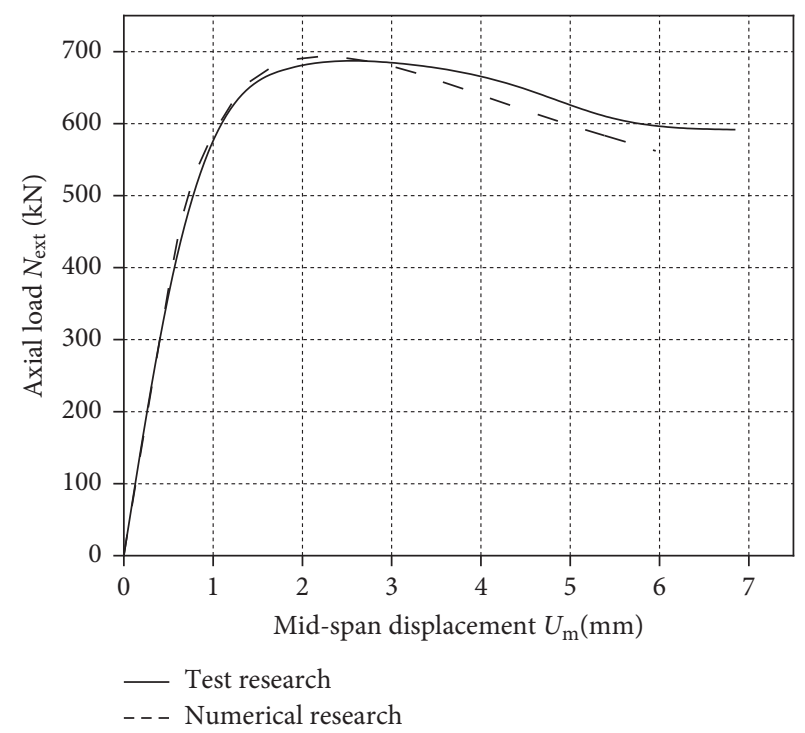

(c)

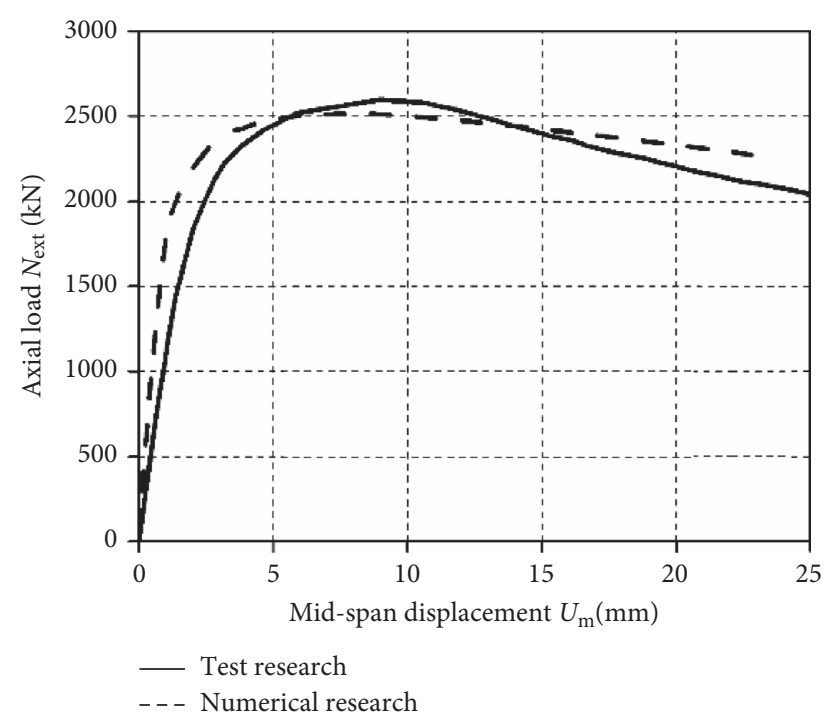

(b)

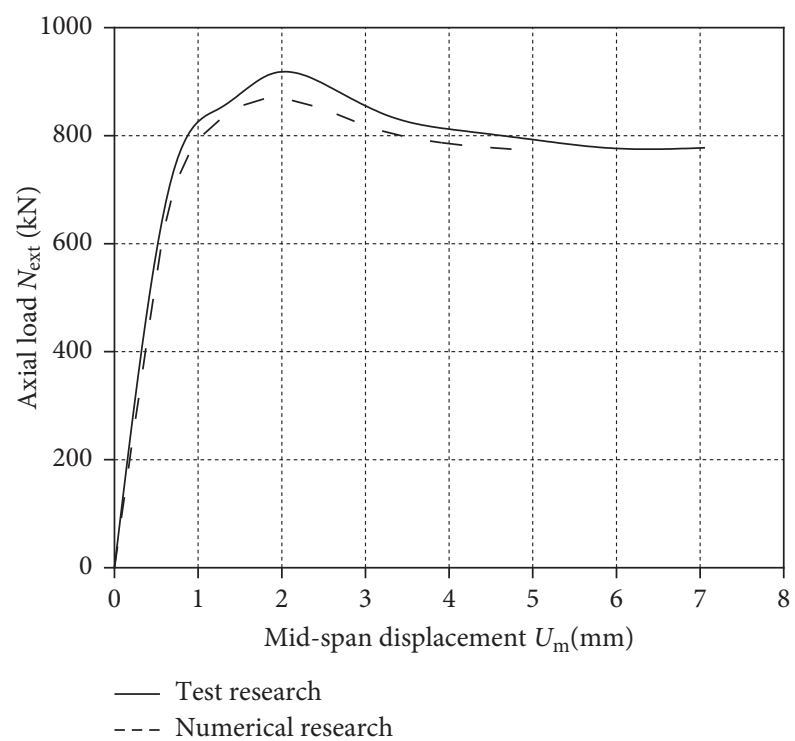

(d)

Figure 6: Comparison of numerical curves and test curves. (a) TE5. (b) TE6. (c) B20-180. (d) B40-180.

(2) The concrete can develop its compressive strength in compressive region but has no strength in tension region; the steel tube can develop its yielding strength in both compressive and tensile regions.

(3) The constraint effect for concrete is considered in the enhancement of concrete compressive strength.

4.1.2. Analysis of Stress Distribution Mode of Cross Section. Based on the preceding numerical analysis, the crosssectional $N-M$ resistance correlation curve has the form described by the curve ABCD in Figure 18. Dotted line 1 is a simplified model of resistance correlation curve proposed by other scholars. A good approach to the numerical results can be expected except for the region near the inflection point $\mathrm{C}$, where the simplified model gives too conservative result. In this paper, simplified dotted line 2 is proposed to approximate the curve $\mathrm{AB}$ with straight line $\mathrm{AB}$ and approximate the curve $\mathrm{BCD}$ with polyline $\mathrm{BCD}$. By comparison, it is observed that line 2 gives better approximation, especially near the inflection point $C$.

On simplified line 2, feature point A corresponds to the cross-sectional axial compressive resistance $N_{0}$ considering the constraint effect; feature point $D$ corresponds to the cross-sectional bending resistance $M_{0}$ considering the constraint effect; feature point $B$ is a point with the same bending resistance with point $D$; feature point $\mathrm{C}$ is the inflection point with the largest bending resistance.

The T-shaped CFST column is monosymmetrical in cross section and has three feature loading directions, that is, positive direction $\left(90^{\circ}\right)$, negative direction $\left(-90^{\circ}\right)$, and $x$ direction $\left(0^{\circ}\right)$. The cross-sectional $N-M$ resistance 


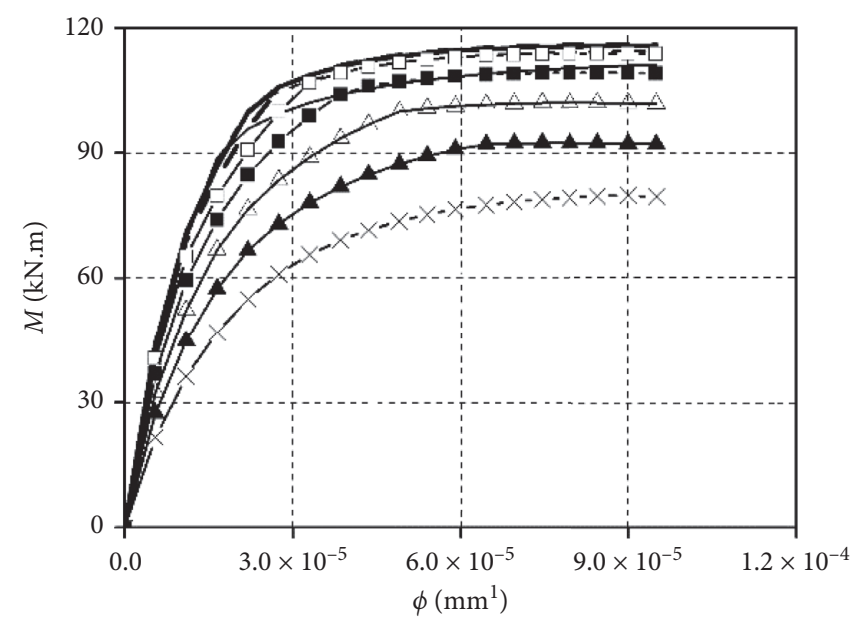

$$
\begin{aligned}
-n & =0.1 \\
--- & n=0.2 \\
-n & =0.3
\end{aligned}
$$$$
\begin{aligned}
& --n=0.4 \\
& \text { - - } n=0.5 \\
& \text { - - } n=0.6
\end{aligned}
$$

(a)

Figure 7: Cross-sectional (M)- $\phi$ relation curves.

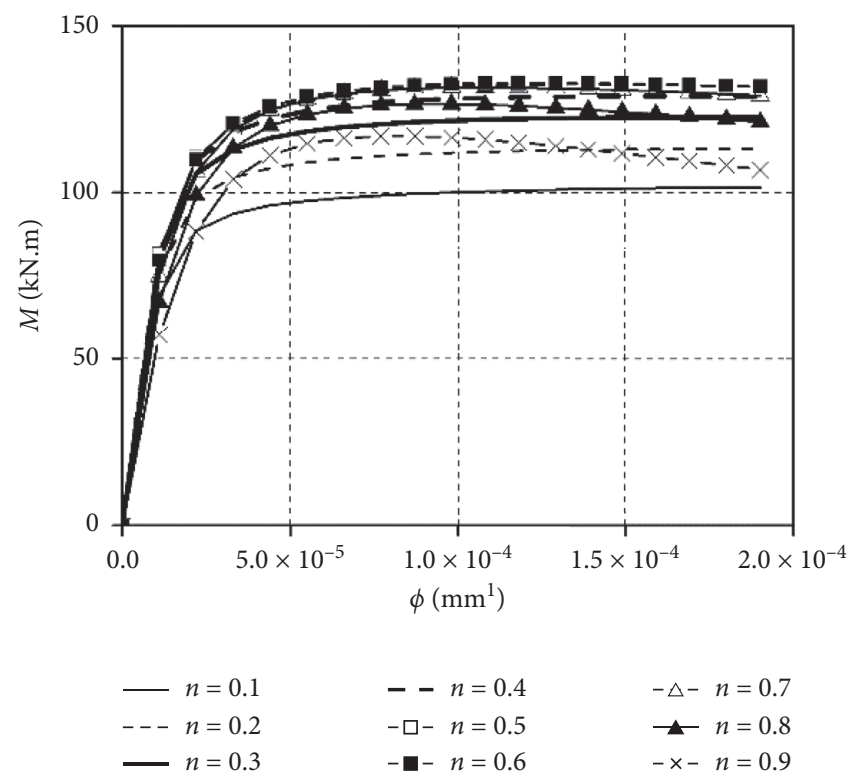

(b)

(a) Forward loading. (b) 45-degree angle loading.

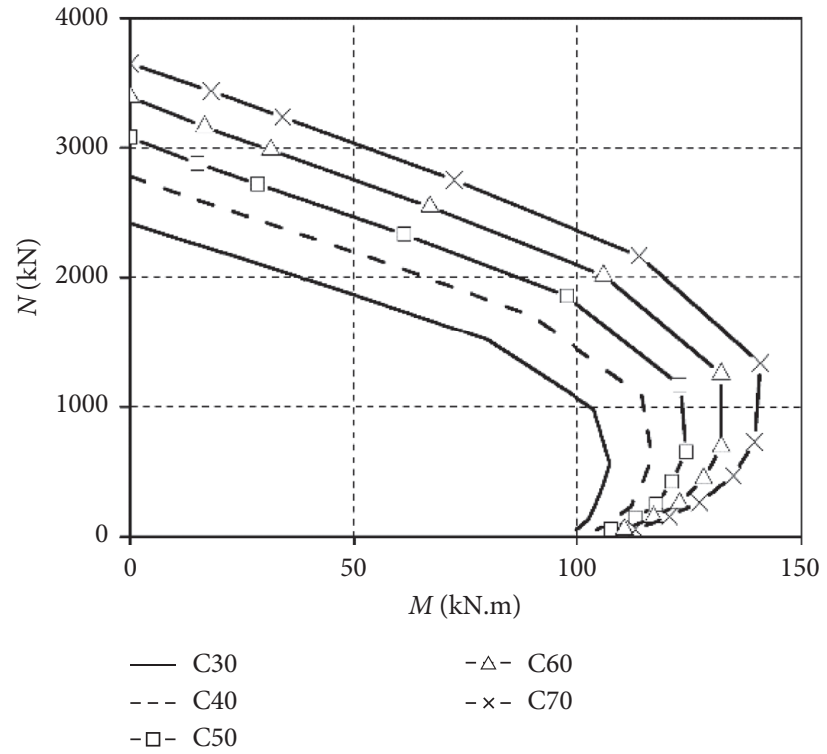

(a)

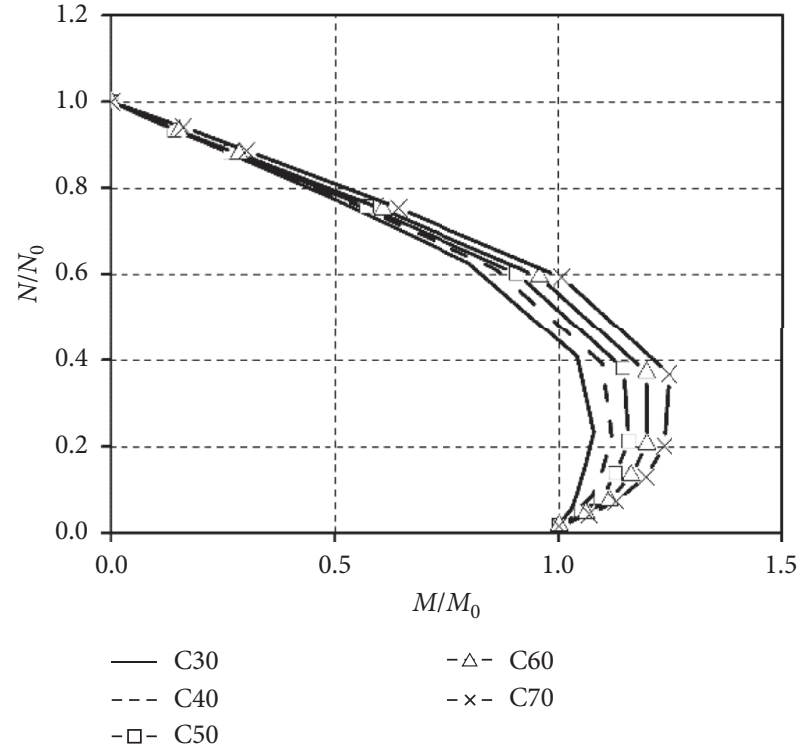

(b)

FIGURE 8: Influence of concrete strength $(f)_{\mathrm{ck}}$ on the resistance correlation curves. (a) Forward loading. (b) Forward loading (normalized).

correlation curves of the three feature loading directions should be computed first as a foundation for that in arbitrary loading direction. In the case of loading in the positive direction (compressive region in the web and tensile region in the flange), the position of neutral axis may lie in three possible regions in the cross section (Figure 19(a)): (1) in the web $\left(L_{2}<y_{1}\right) ;(2)$ in the flange steel plate with a length of $L_{3}$
$\left(L_{2}-t \leq y_{1} \leq L_{2}\right) ;(3)$ in the flange concrete $\left(t<y_{1}<L_{2}-t\right)$. In the case of loading in the negative direction and $x$ direction, the neutral axis positions are illustrated in Figures 19(b) and 19(c).

The coordinate $y$ (or $x$ ) should be preset to assume the neutral axis position and calculate the cross-sectional resistance $N$ and $M$ : 


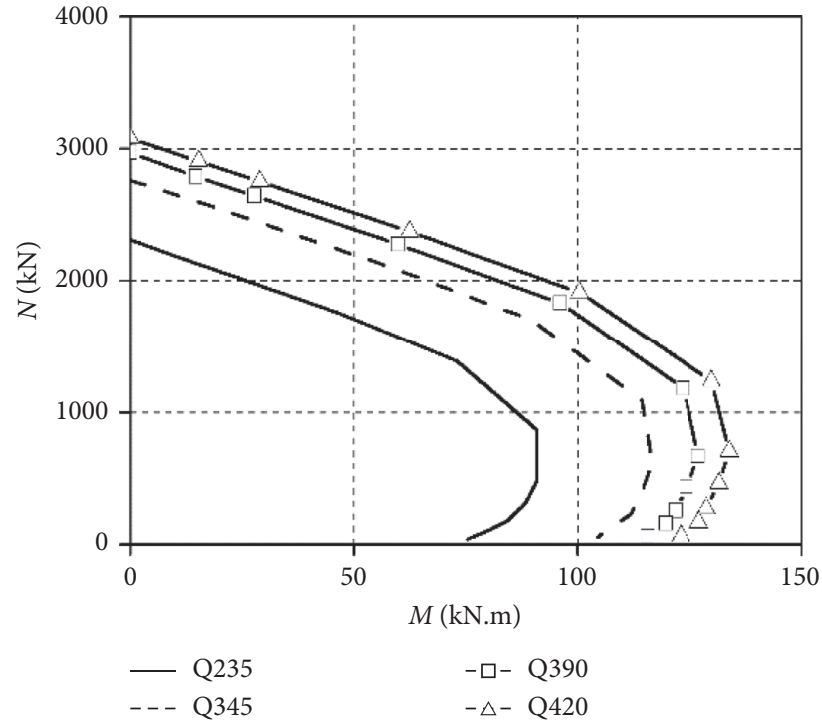

(a)

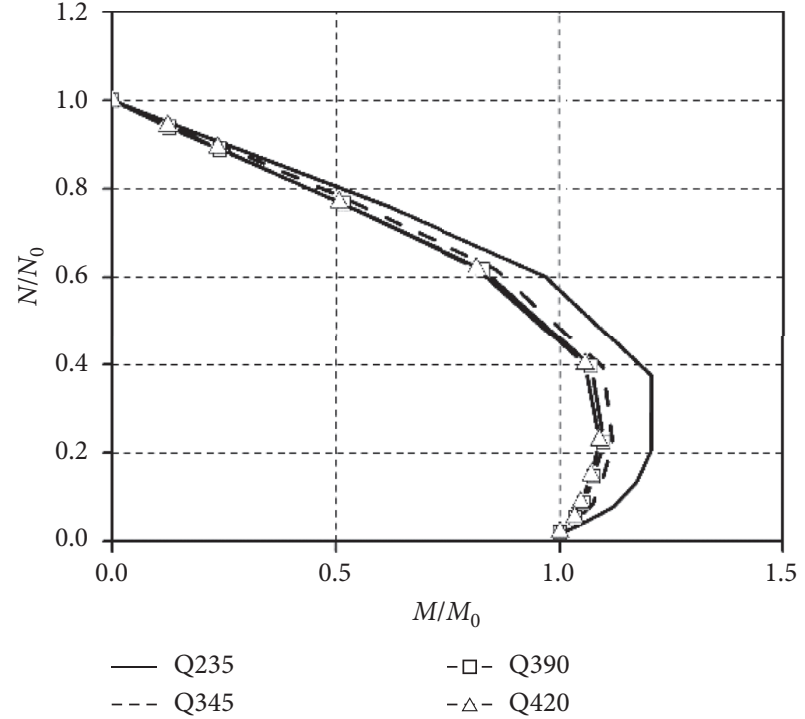

(b)

Figure 9: Influence of steel yielding strength $(f)_{y}$ on the resistance correlation curves. (a) Forward loading. (b) Forward loading (normalized).

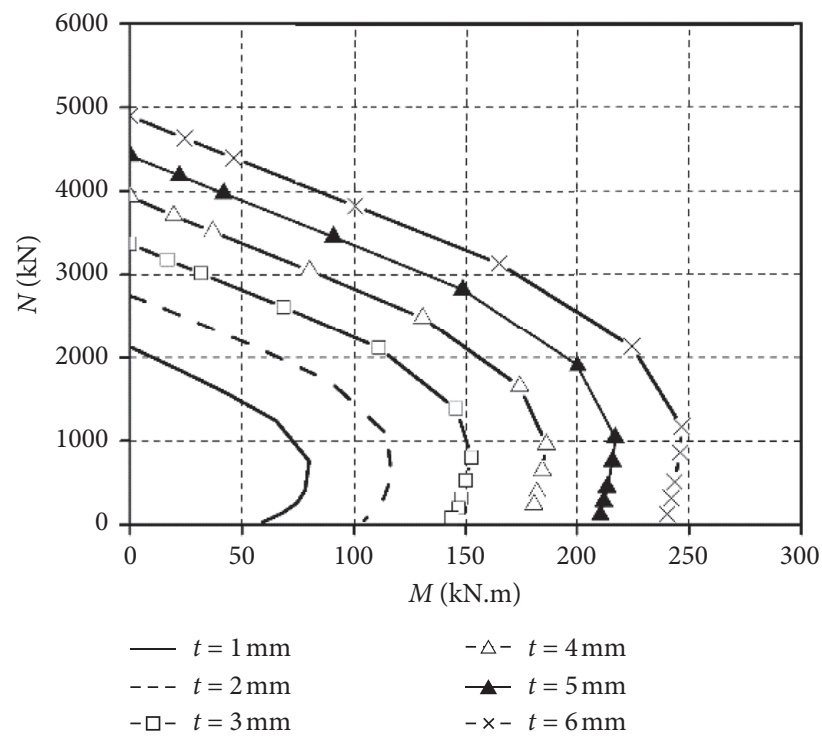

(a)

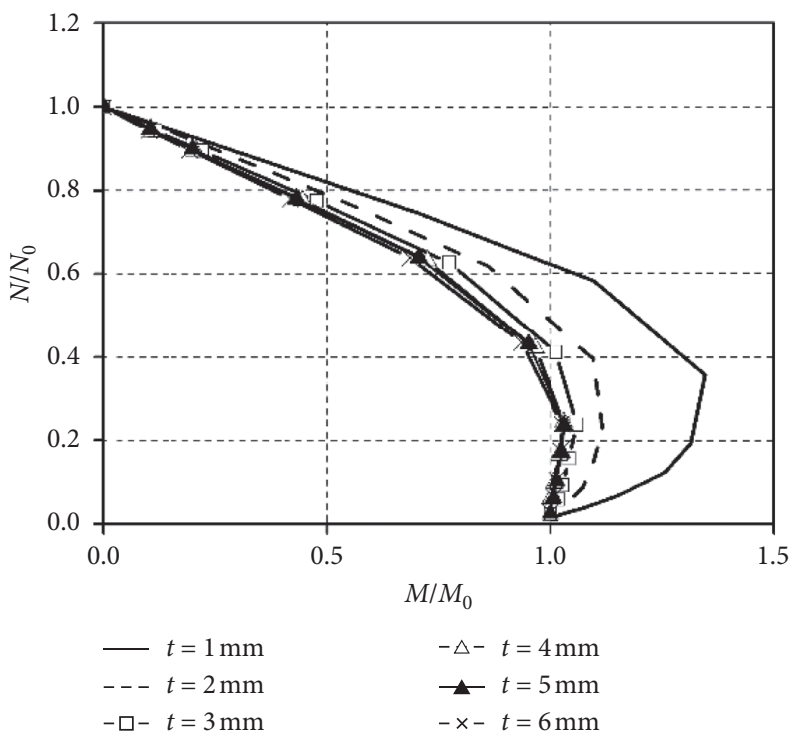

(b)

FIGURE 10: Influence of steel tube thickness t on the resistance correlation curves. (a) Forward loading. (b) Forward loading (normalized).

$$
\begin{aligned}
& N=\sum_{i=1}^{1} f_{c c} A_{c i}+\sum_{j=1}^{m} f_{y} A_{\mathrm{sci}}-\sum_{k=1}^{n} f_{y} A_{\mathrm{sti}}, \\
& M=\sum_{i=1}^{l} f_{c c} A_{c i} y_{c i}+\sum_{j=1}^{m} f_{y} A_{\mathrm{sci}} y_{\mathrm{sci}}+\sum_{k=1}^{n} f_{y} A_{\mathrm{sti}} y_{\mathrm{sti}},
\end{aligned}
$$

where $A_{\mathrm{ci}}, A_{\mathrm{sci}}$, and $A_{\mathrm{sti}}$ are, respectively, element areas of compressive concrete, compressive steel, and tensile steel; $y_{\mathrm{ci}}$, $y_{\text {sci }}$ and $y_{\text {sti }}$ are, respectively, distances of compressive concrete, compressive steel, and tensile steel away from neutral axis. If $N$ equals axial load $N_{\text {ext }}$, then the preset $y$ (or $x$ ) and corresponding cross-sectional resistance $N$ and $M$ can be accurately determined. If not, the $y$ (or $x$ ) should be preset again, and iteration will be carried out until appropriate $y$ (or $x$ ) is acquired.

For the determination of the location of feature points $A$, $B, C$, and $D$ in Figure 18, the specific calculation steps are as follows: 


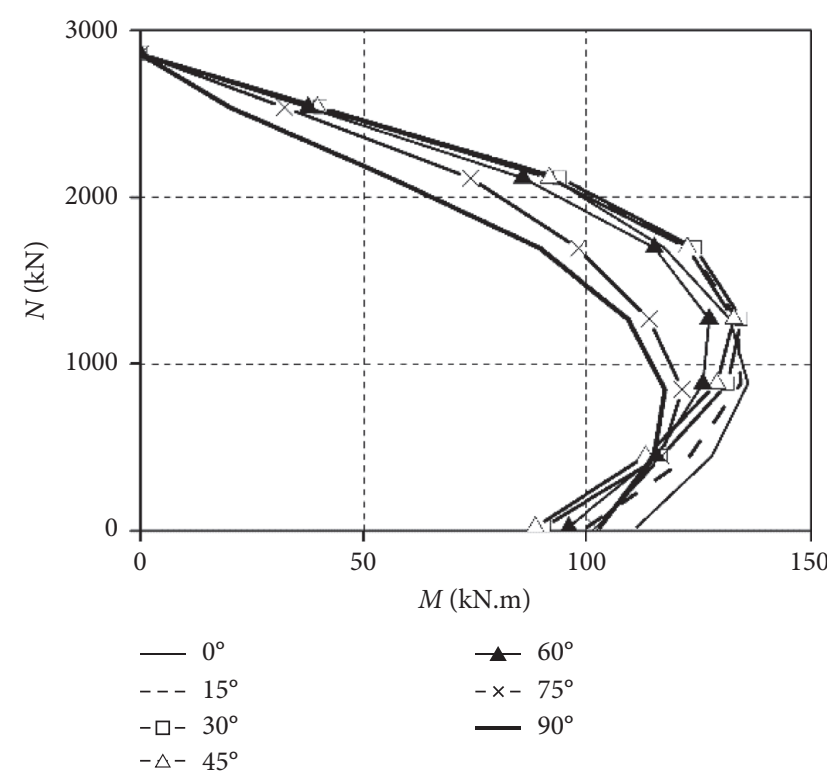

(a)

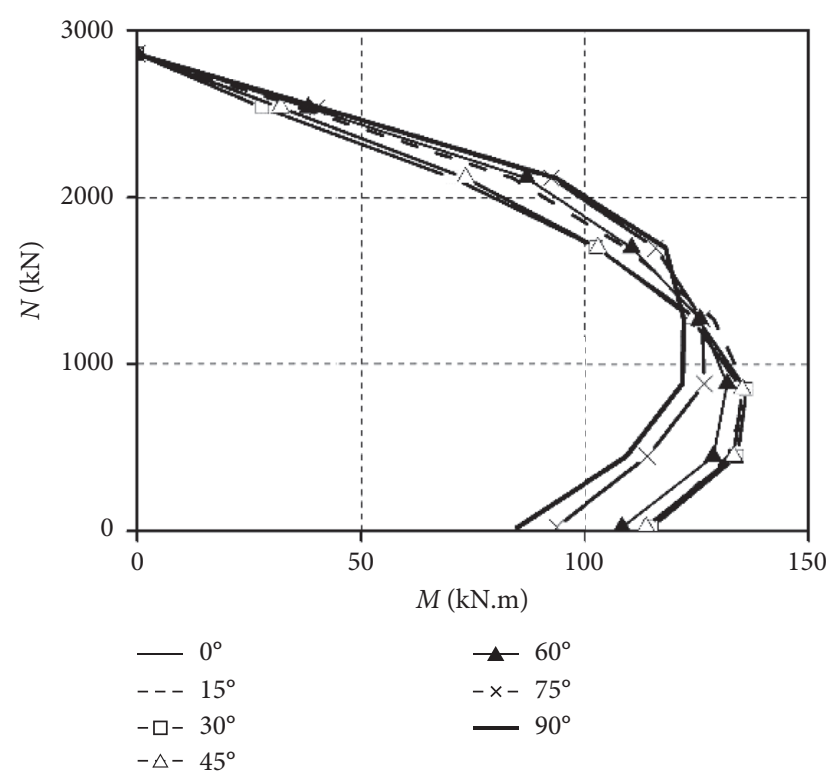

(b)

Figure 11: Influence of loading angle $\theta$ on the resistance correlation curves. (a) Positive angle loading. (b) Negative angle loading.

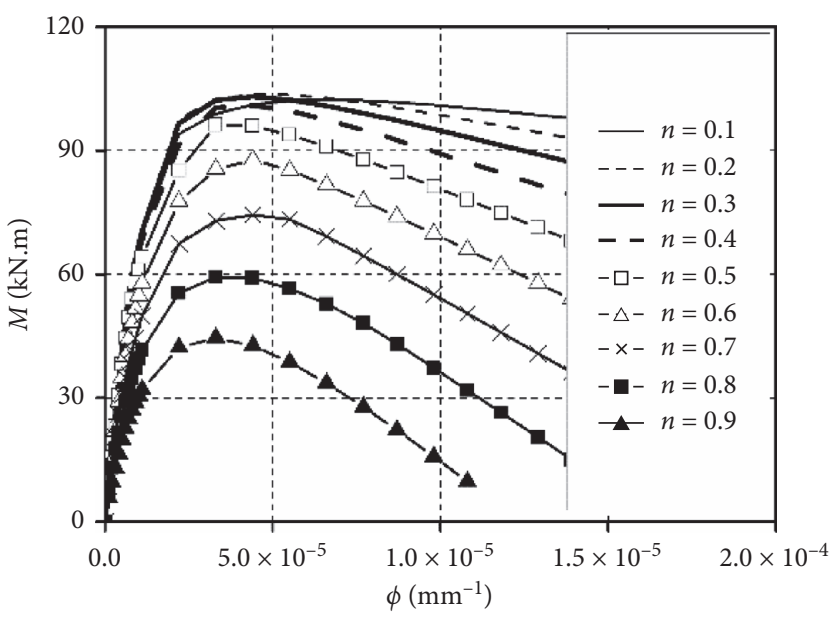

(a)

Figure 12: Component-based $M-\phi$ relation curves.

(a) Calculate the position of feature point A. A design method of axial compressive bearing capacity $N_{0}$ of T-shaped CFST stub columns is proposed considering constraint effect coefficient $\xi$ () based on the unified theory. A total of 120 special-shaped CFST stub columns with constraint effect coefficient $\xi$ range of $0.5-4.0$ are simulated with the numerical program. The parameters are listed in Table 1.

The unified theory considers the steel tube and concrete as a new composite material, considering constraint effect for concrete provided by steel tube [31]. The calculated values of numerical program are shown in Figure 20. The $f_{\mathrm{sc}} / f_{\mathrm{ck}}$ and $\xi$ are,

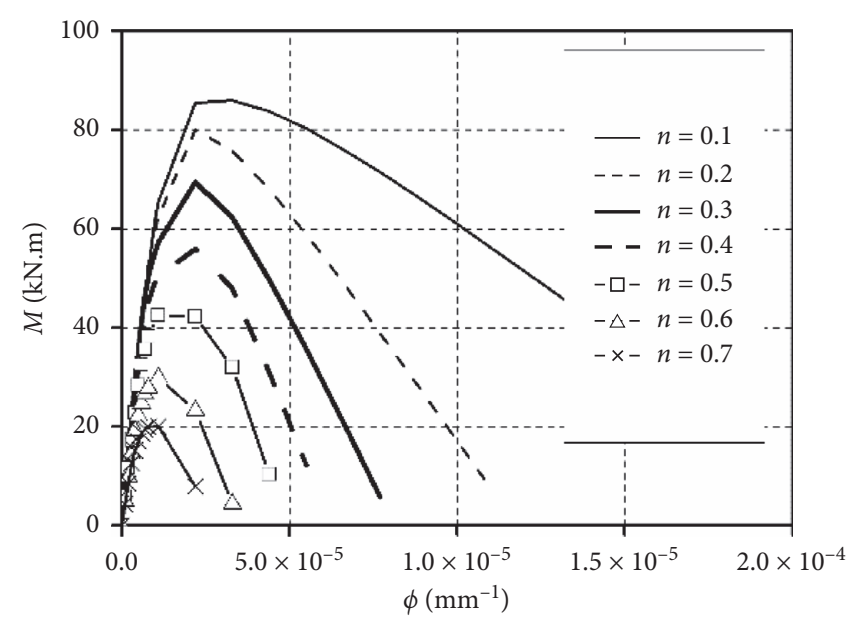

(b)

(a) Slenderness ratio of 20. (b) Slenderness ratio of 100.

respectively, taken as the vertical axis and the horizontal axis. The composite strength $f_{\text {sc }}$ is the ratio of the calculated axial bearing capacity of stub column to total cross-sectional area $A_{\mathrm{sc}}$ $\left(A_{\mathrm{sc}}=A_{\mathrm{s}}+A_{\mathrm{c}}\right)$. Through regression analysis, the composite strength $f_{\mathrm{sc}}$ of T-shaped CFST stub column is determined by equation (2) with red line expressed in Figure 19. The coefficients $B$ and $C$ are, respectively, used to consider the influences of steel yield strength and concrete strength (equation (3)). Then, the axial compressive bearing capacity of T-shaped CFST stub columns can be calculated with equation (4). 


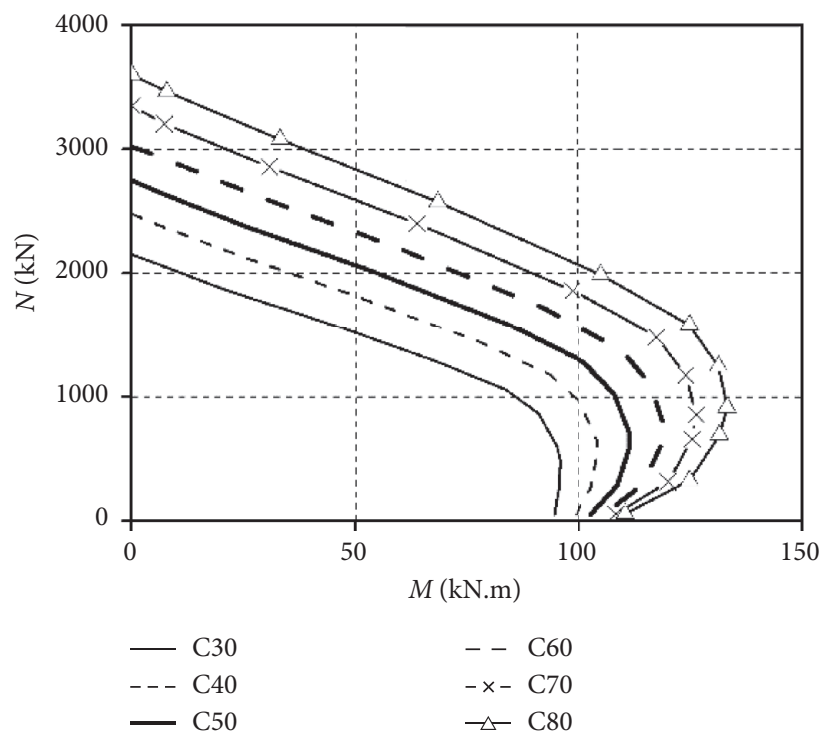

(a)

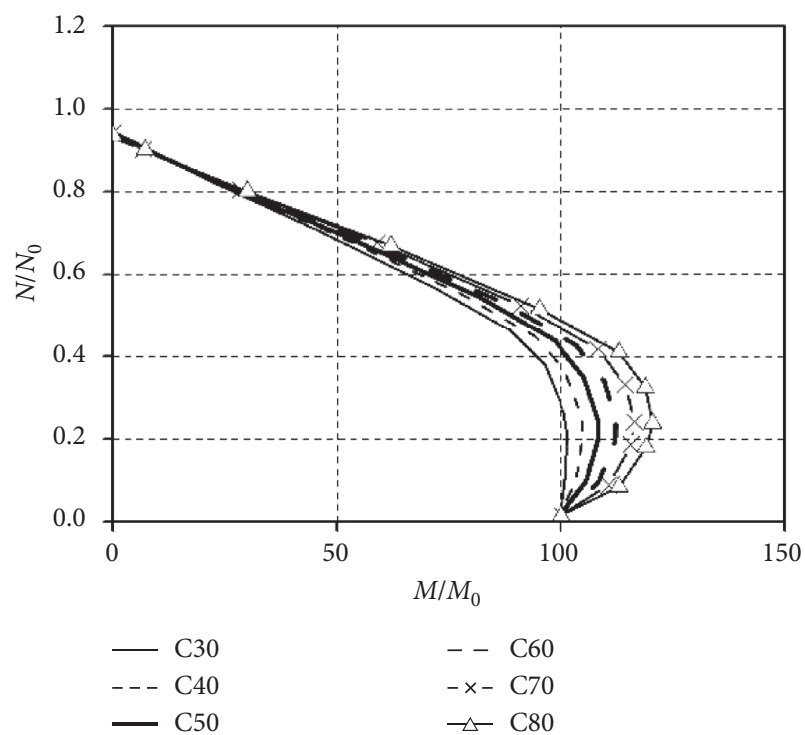

(b)

FIGURE 13: Influence of concrete strength $(f)_{\mathrm{ck}}$ on component-based resistance correlation curves. (a) Slenderness ratio of 20. (b) Slenderness ratio of 20 (normalized).

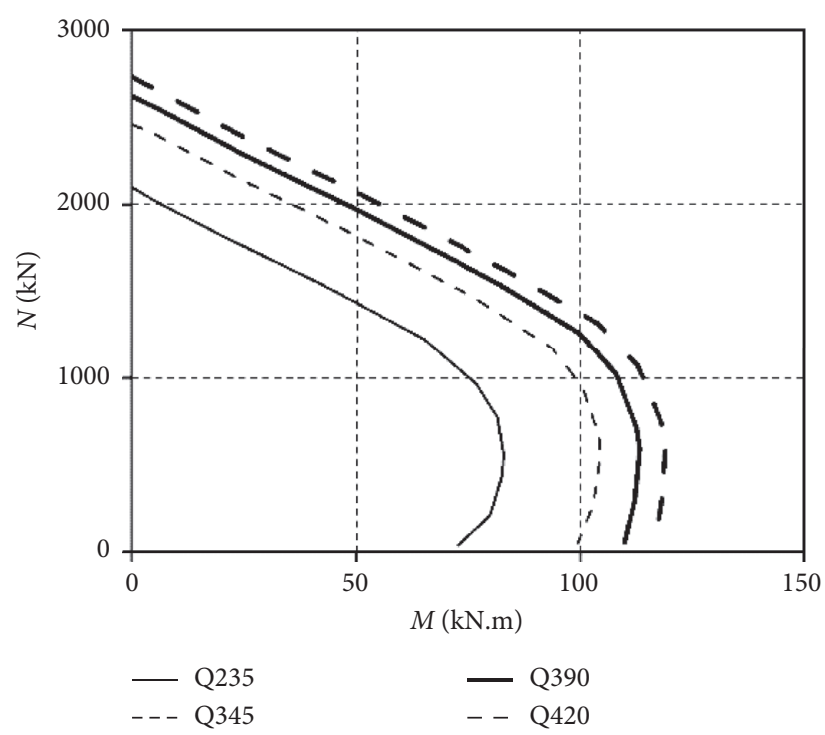

(a)

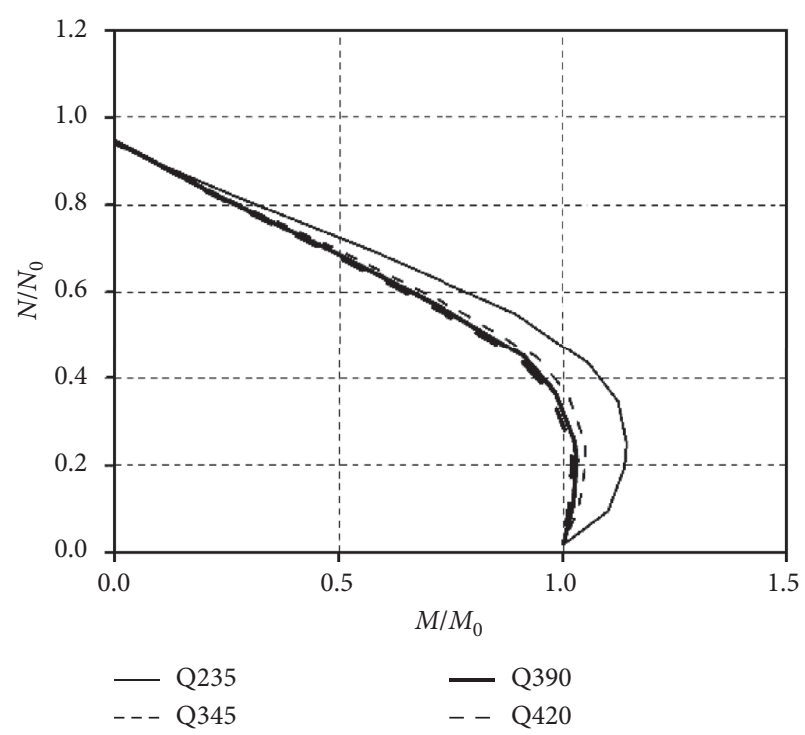

(b)

FIGURE 14: Influence of steel yielding strength fy on component-based resistance correlation curves. (a) Slenderness ratio of 20. (b) Slenderness ratio of 20 (normalized).

$$
\begin{aligned}
f_{\mathrm{sc}} & =\left(C \xi^{2}+B \xi+1.0\right) f_{\mathrm{ck}} \\
B & =\frac{0.115 f_{y}}{235}+0.7 \\
C & =\frac{-0.011 f_{c k}}{20}+0.01 \\
N_{0} & =A_{\mathrm{sc}} f_{\mathrm{sc}}
\end{aligned}
$$

(b) Calculate the position of feature point D. Arbitrarily assuming a cross-sectional stress distribution, the neutral axis position ( $y$-value) can be calculated from the cross section internal force $N=0$. If the $y$-value coincides with the cross section stress distribution, the position of the point $D$ is determined, and the cross section internal moment $M$ is calculated according to the $y$-value, then $M_{0}=M$; if not, the cross-sectional stress distribution is assumed again, 


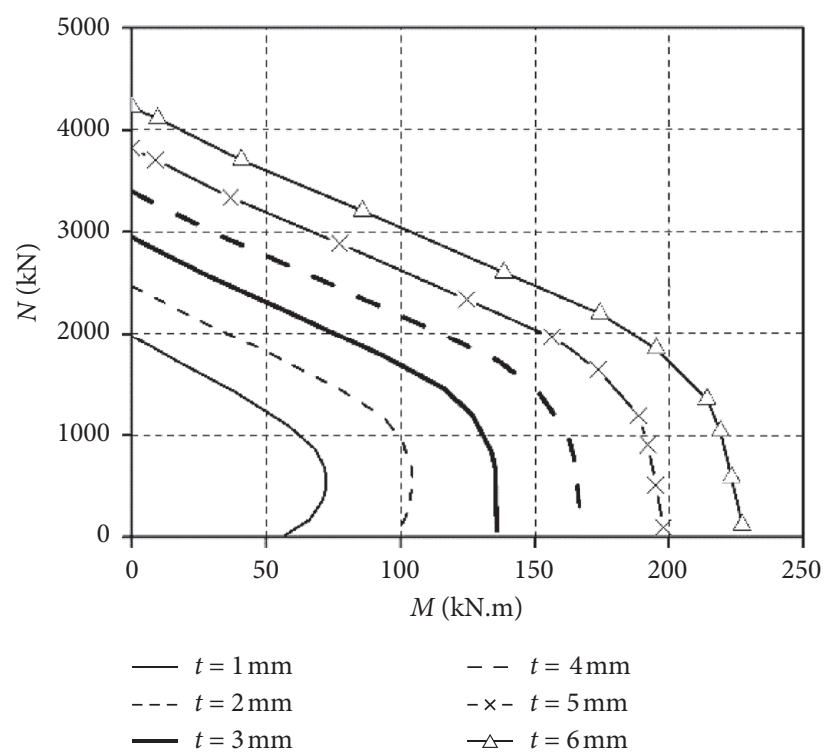

(a)

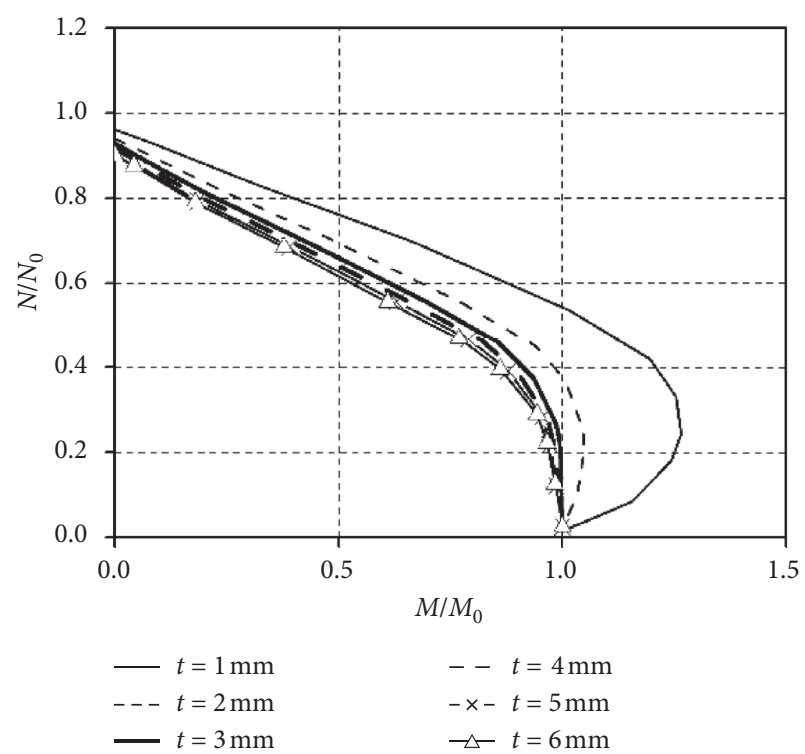

(b)

FIGURE 15: Influence of steel tube thickness $t$ on the component-based resistance correlation curves. (a) Slenderness ratio of 20. (b) Slenderness ratio of 20 (normalized).

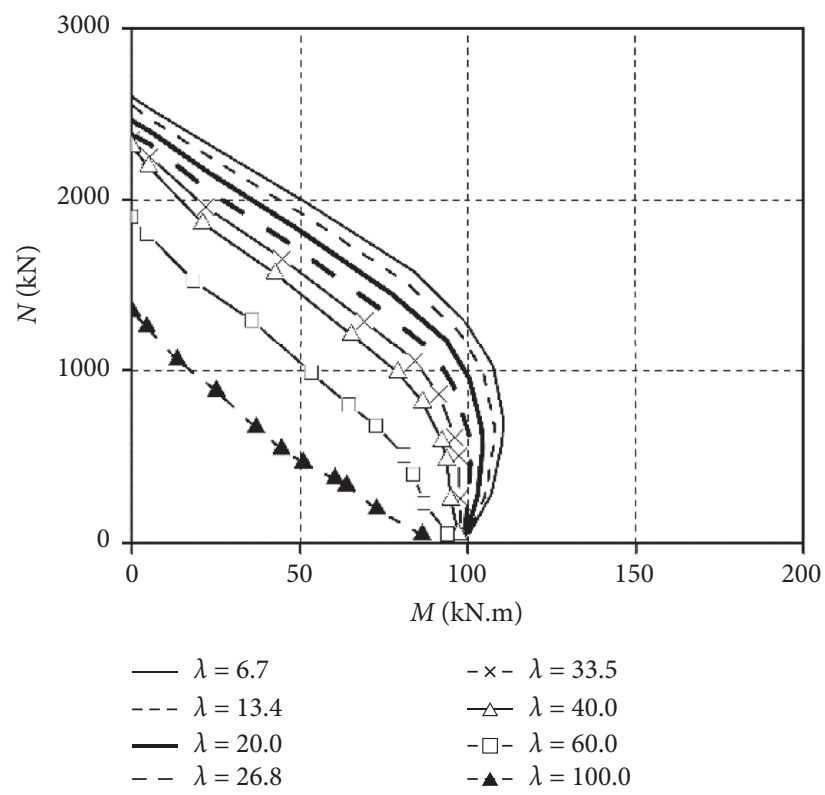

(a)

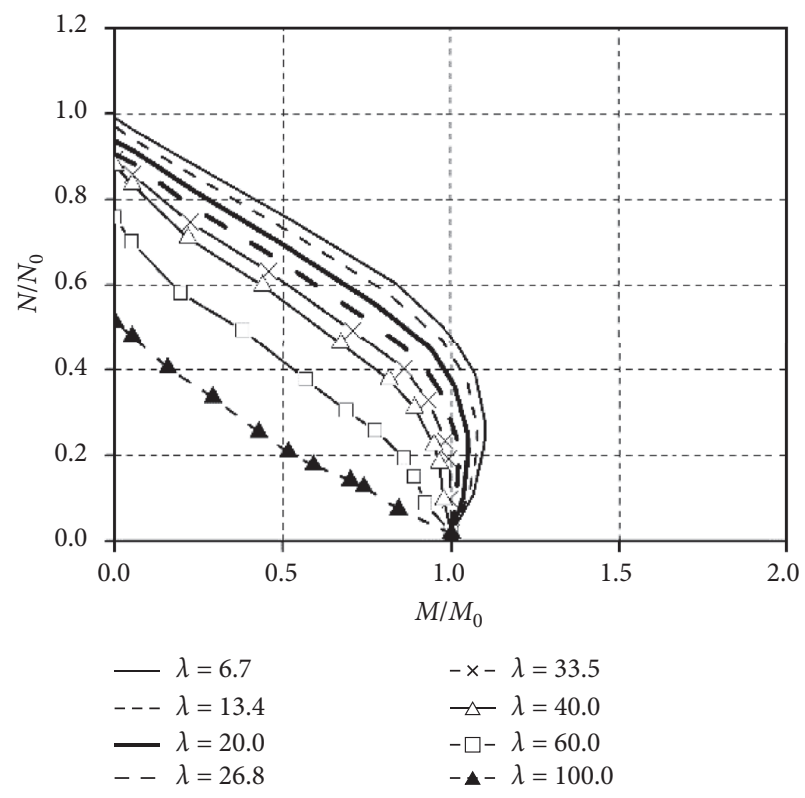

(b)

FIGURE 16: Influence of slenderness ratio $\lambda$ on the component-based resistance correlation curves. (a) Forward loading. (b) Forward loading (normalized).

and the position of the neutral axis (y-value) will be calculated until the section neutral axis position coincides with the cross section stress distribution, and the bending moment $M_{0}$ at the point $D$ is determined.

(c) Calculate the position of feature point B. Using the method of step (b), calculate another axial compressive bearing capacity $N_{\mathrm{b}}$ corresponding to bending moment $M_{0}$, and obtain the position of point B $\left(M_{0}, N_{\mathrm{b}}\right)$.

(d) Calculate the position of feature point C. Assume that the axial compressive bearing capacity of point C $N_{c}=N_{b} / 2$, using the method of step (b) to calculate the section neutral axis position, and then calculate 


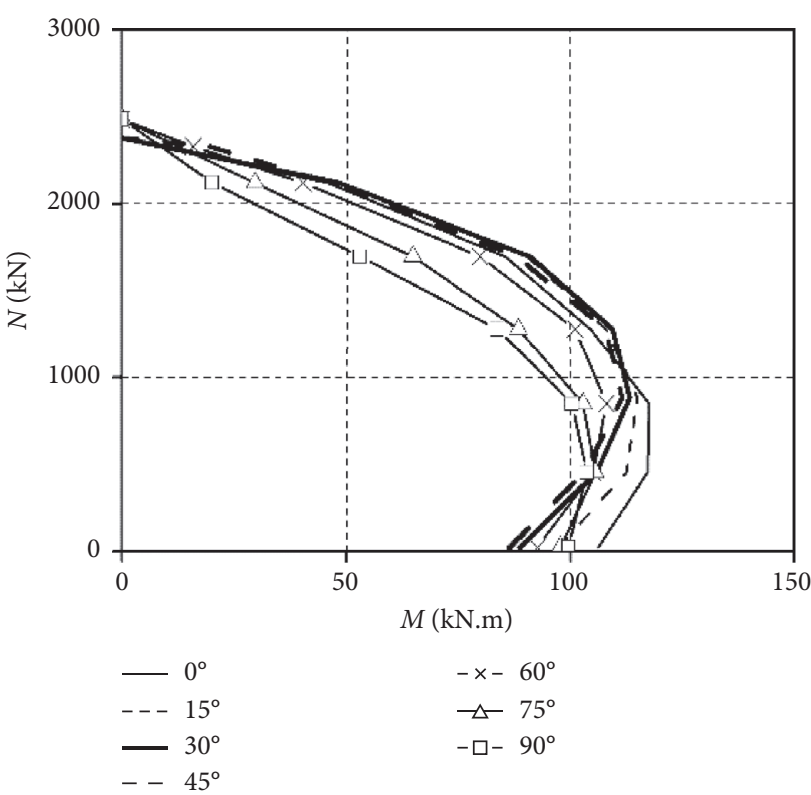

(a)

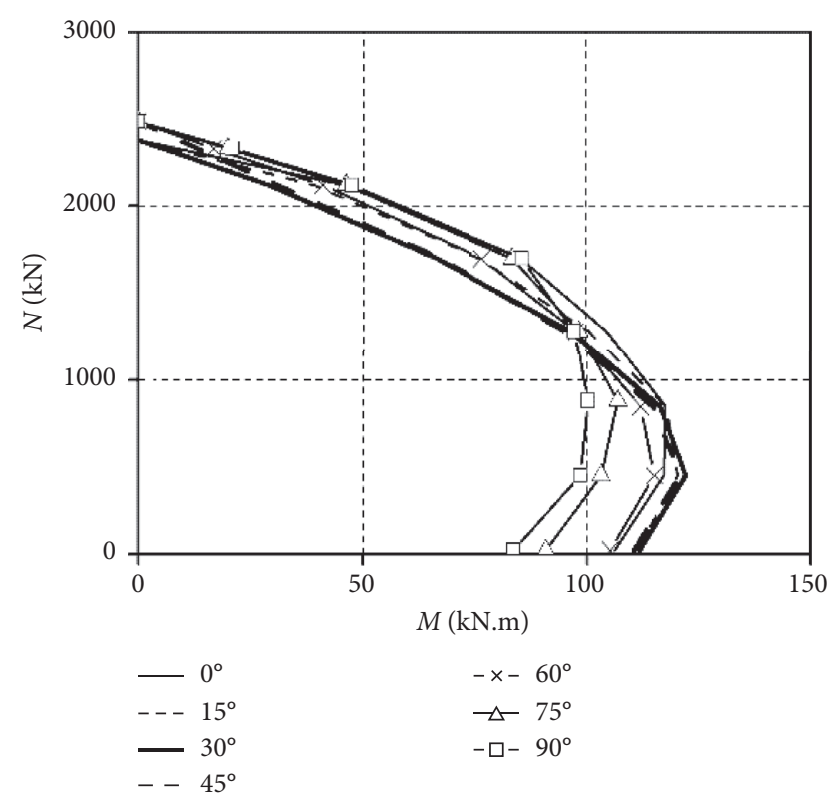

(b)

FIgURE 17: Influence of loading angle $\theta$ on the component resistance correlation curves. (a) Positive angle loading. (b) Negative angle loading.

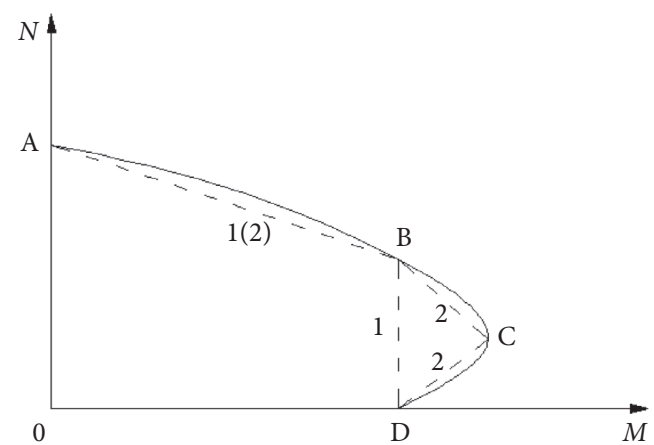

FIgURe 18: Simplified model of cross-sectional $N-M$ resistance correlation curves.

the corresponding bending resistance $M_{\mathcal{c}}$, to obtain the position of point $C\left(M_{\mathrm{c}}, N_{\mathrm{c}}\right)$.

After determination of feature points $A, B, C$ and $D$, the simplified model of $N-M$ resistance correlation curves can be obtained by connecting feature points in formulas (5), (6), and (7).

$$
\begin{aligned}
& \mathrm{AB}: \frac{N-N_{\mathrm{b}}}{N_{0}-N_{\mathrm{b}}}+\frac{M}{M_{\mathrm{b}}} \leq 1, \\
& \mathrm{BC}: \frac{N}{N_{\mathrm{c}}}+\frac{M-M_{\mathrm{c}}}{M_{\mathrm{c}}-M_{\mathrm{b}}} \leq 1, \\
& \mathrm{CD}: \frac{N}{N_{\mathrm{c}}}+\frac{M-M_{\mathrm{c}}}{M_{0}-M_{\mathrm{c}}} \leq 1 .
\end{aligned}
$$

In terms of biaxial eccentrically compressive cross sections, each feature point is regressed on the basis of those in the neighboring two feature uniaxial directions. To be mentioned conveniently in the following contents, the coordinates of feature points in positive direction, in negative direction, and in $x$ direction are, respectively, denoted with label $(+),(-)$, and $(0)$.

The bending resistance $M_{0}$ of point $D$ under biaxial eccentric compression needs considering the impact of loading angle $\theta$. The $M_{0}$ is regressed by correcting $M_{0}(+)$, with correction factor $f_{1}$ expressed in equation (9).

$$
\begin{aligned}
M_{0} & =f_{1} M_{0}(+), \\
f_{1} & =6 \times 10^{-7} \theta^{3}-2 \times 10^{-5} \theta^{2}-3.4 \times 10^{-3} \theta+1.04 .
\end{aligned}
$$

The bending resistance $M_{\mathrm{b}}$ of point B under arbitrary loading angle $\theta$ (excluding three feature uniaxial directions) is estimated with an elliptical curve determined by the $M_{\mathrm{b}}$ in feature loading directions. It can be calculated with the following two formulas, respectively, for positive loading angle $\left(0^{\circ}-90^{\circ}\right)$ and negative loading angle $\left(-90^{\circ}-0^{\circ}\right)$ :

$$
\begin{aligned}
& M_{\mathrm{b}}=\sqrt{\left(M_{\mathrm{b}}(0) \cos \theta\right)^{2}+\left(M_{\mathrm{b}}(+) \sin \theta\right)^{2}}, \\
& M_{\mathrm{b}}=\sqrt{\left(M_{\mathrm{b}}(0) \cos \theta\right)^{2}+\left(M_{\mathrm{b}}(-) \sin \theta\right)^{2}} .
\end{aligned}
$$

The axial compressive resistance $N_{\mathrm{b}}$ of point B under arbitrary loading angle $\theta$ is regressed with a straight line determined by the $N_{\mathrm{b}}$ in feature loading directions. The formula of $N_{\mathrm{b}}$ under arbitrary loading angle $\theta$ is expressed 

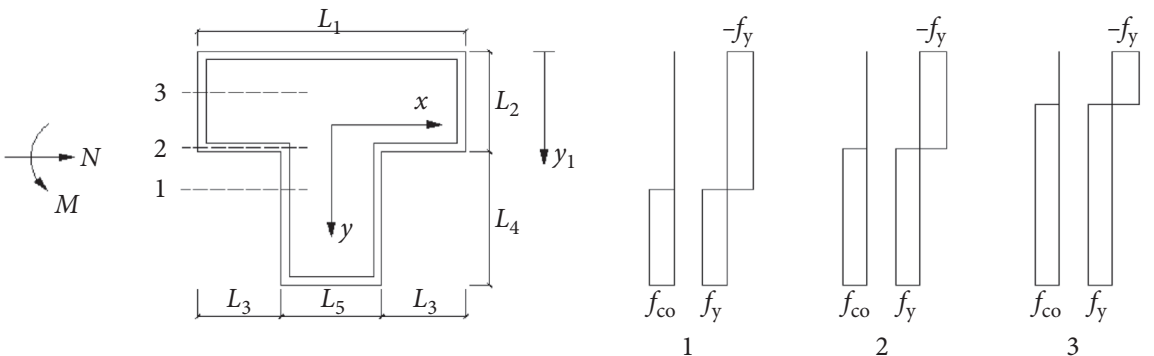

(a)
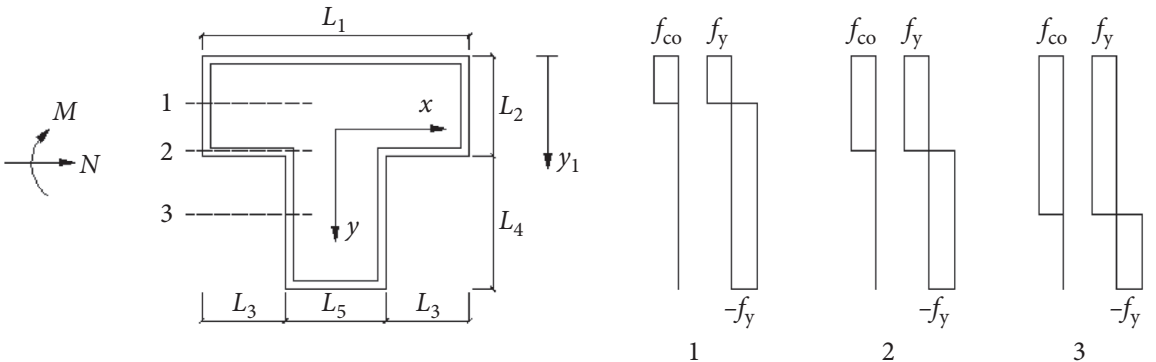

(b)
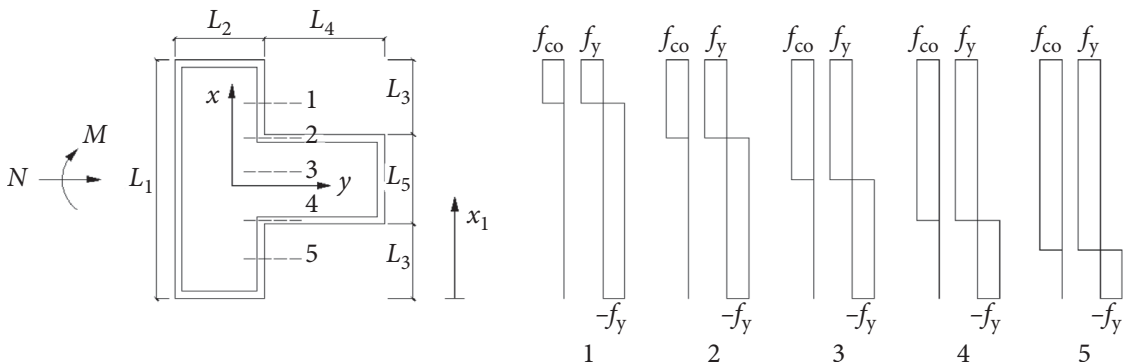

(c)

FIgURE 19: Cross-sectional stress distribution. (a) In forward direction loading. (b) In reverse direction loading. (c) In $x$ direction loading.

TABLE 1: The parametric values.

\begin{tabular}{lccc}
\hline Parameter & Values & $\begin{array}{c}\text { Fixed } \\
\text { value }\end{array}$ & Range of $\xi$ \\
\hline$t(\mathrm{~mm})$ & $1,2,3,4,5,6$ & 2 & \\
$f_{\mathrm{ck}}(\mathrm{MPa})$ & $20.1,26.8,32.4,38.5$, & 26.8 & $\xi=A_{s} f_{y} / A_{c} f_{c k}$ \\
$f_{\mathrm{y}}(\mathrm{MPa})$ & 234.5 & $0.5-4.0)$
\end{tabular}

with equations (11) and (12), respectively, for positive loading angle $\left(0^{\circ}-90^{\circ}\right)$ and negative loading angle $\left(-90^{\circ}-0^{\circ}\right)$ :

$$
\begin{aligned}
& N_{b}=N_{b}(0)+\frac{\theta}{90}\left(N_{b}(+)-N_{b}(0)\right), \\
& N_{b}=N_{b}(0)+\frac{\theta}{90}\left(N_{b}(-)-N_{b}(0)\right) .
\end{aligned}
$$

Except for loading angle $\theta$, the impact of constraint effect is suggested to be taken into consideration, and a correction expression $\Delta N_{\mathrm{b}}$ should be subtracted from $N_{\mathrm{b}}$ :

$$
\begin{aligned}
\Delta N_{b} & =1.29 \times 10^{5} \times 2.72^{(0.845 \xi),} \\
N_{b} & =N_{b}-\Delta N_{b} .
\end{aligned}
$$

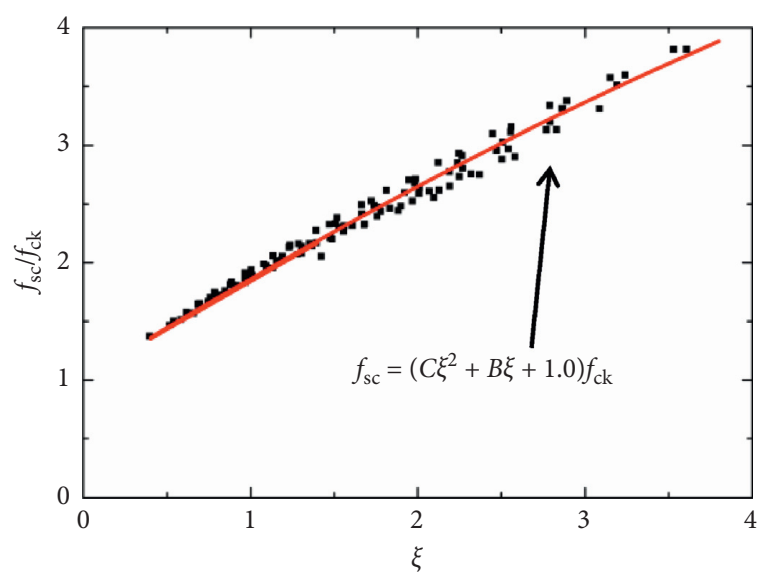

Figure 20: $(f)_{\mathrm{sc}} /(f)_{\mathrm{ck}}-\xi$ curves.

The bending resistance $M_{\mathrm{c}}$ of point $\mathrm{C}$ under arbitrary loading angle $\theta$ is estimated with expressions (14) and (15), respectively, for positive loading angle $\left(0^{\circ}-90^{\circ}\right)$ and negative loading angle $\left(-90^{\circ}-0^{\circ}\right)$ : 


$$
\begin{aligned}
M_{c}= & \left(-2 \times 10^{-5} \theta^{2}+1.7 \times 10^{-3} \theta+0.965\right) \\
& \cdot \sqrt{\left(M_{c}(0) \cos \theta\right)^{2}+\left(M_{c}(+) \sin \theta\right)^{2}}, \\
M_{c}= & \left(10^{-5} \theta^{2}-1.3 \times 10^{-3} \theta+0.942\right) \\
& \cdot \sqrt{\left(M_{c}(0) \cos \theta\right)^{2}+\left(M_{c}(-) \sin \theta\right)^{2}} .
\end{aligned}
$$

The axial compressive resistance $N_{c}$ of point $\mathrm{C}$ under arbitrary loading angle $\theta$ is regressed with a straight line determined by the $N_{\mathrm{c}}$ in feature loading directions. It can be expressed in the formulas (16) and (17), respectively, for positive loading angle $\left(0^{\circ}-90^{\circ}\right)$ and negative loading angle $\left(-90^{\circ}-0^{\circ}\right)$ :

$$
\begin{aligned}
& N_{c}=N_{c}(0)+\frac{\theta}{90}\left(N_{c}(+)-N_{c}(0)\right), \\
& N_{c}=N_{c}(0)+\frac{\theta}{90}\left(N_{c}(-)-N_{c}(0)\right) .
\end{aligned}
$$

After determination of the feature points A, B, C and D under arbitrary loading angle $\theta$, the formulas $(5) \sim(7)$ can be also adopted as simplified resistance model under arbitrary loading angle $\theta$.

4.1.3. Comparison of Simplified Resistance Model and Numerical Results. The simplified model is used to calculate the cross-sectional resistance correlation curves and compared with the numerical results in Figures 21 and 22. The comparison involves parameters of concrete strength $f_{\mathrm{ck}}$ (C30, C50, and C70), steel yielding strength $f_{\mathrm{y}}(\mathrm{Q} 235, \mathrm{Q} 345$, and Q420), steel tube thickness $t(2 \mathrm{~mm}, 4 \mathrm{~mm}$, and $6 \mathrm{~mm})$, and loading angle $\theta\left(-90^{\circ}-90^{\circ}\right)$. The concrete strength C30 (according to a concrete structure code in China GB500102002) represents a characteristic value of compressive strength for prismatic standard test blocks. The steel yielding strength Q235 can refer to a steel structure code in China (GB50017-2003).

Figures 21 and 22 show that the simplified resistance model has adequate agreement with the numerical results. The correlation curve of simplified resistance model is approximately enveloped by a corresponding numerical correlation curve, which reveals that the simplified model is a little conservative and can be adopted to predict the static behavior of special-shaped stiffened CFST columns subjected to eccentrically compressive load.

4.2. Simplified Resistance Model of Eccentrically Compressive Column. The simplified resistance model for column is introduced in Figure 23. Curve 1 is the numerical result; bilinear curve 2 is the proposed simplified resistance model. $N_{\mathrm{z}}$ is the cross-sectional axial compressive resistance considering constraint effect, which is the same as $N_{0} ; \varphi$ is the stability coefficient considering length impact, calculated with the following formula:

$$
\begin{aligned}
& \varphi= \begin{cases}1.0, & \left(\lambda \leq \lambda_{0}\right), \\
-3 \times 10^{-5} \lambda-0.0016 \lambda+1, & \left(\lambda_{0}<\lambda \leq \lambda_{p}\right), \\
11106 /(\lambda+40)^{2}, & \lambda>\lambda_{p},\end{cases} \\
& \lambda_{0}=\pi \sqrt{\frac{(220 \theta+450)}{\left[(0.85 \theta+1.18) f_{c k}\right]},} \\
& \lambda_{p}=\frac{1932}{\sqrt{f_{y}}} .
\end{aligned}
$$

$M_{0}{ }^{\prime}$ is the bending resistance of columns, modified from cross-sectional bending resistance $M_{0}$.

$$
M_{0}^{\prime}=f_{\text {angle }} f_{\xi} M_{0} .
$$

The $f_{\text {angle }}$ and $f_{\xi}$ are, respectively, the modification coefficients considering the impact of loading angle $\theta$ and constraint coefficient $\xi$.

$$
\begin{aligned}
f_{\text {angle }}= & 0.055 \sin \left(\frac{-5.5 \theta \pi}{180}+1.9\right)+0.95\left(0 \leq \theta \leq 90^{\circ}\right), \\
f_{\text {angle }}= & -5 \times 10^{-7} \theta^{3}-4 \times 10^{-5} \theta^{2}+7 \times 10^{-4} \theta \\
& +1.016\left(-90^{\circ} \leq \theta \leq 0\right), \\
f_{\xi}= & 0.132 \xi+0.91 .
\end{aligned}
$$

$M_{\mathrm{c}}$ and $N_{\mathrm{c}}$ are, respectively, bending resistance and axial compressive resistance of inflection point C. Regressed by numerical results, $N_{c}$ is approximated with $0.3 N_{c}$, which gives a simple and accurate approach. $M_{c}$ is the modified form of $M_{0}$, with modification coefficients $f_{\text {angle }}, f_{l}$ and $f_{\xi}$, respectively, considering the impact of loading angle $\theta$, the length of column $L$, and constraint coefficient $\xi$.

$$
\begin{aligned}
M_{c} & =f_{\text {angle }}^{\prime} f_{l}^{\prime} f_{\xi}^{\prime} M_{0}^{\prime}, \\
f_{\text {angle }}^{\prime} & =-6 \times 10^{-7} \theta^{3}-4 \times 10^{-6} \theta^{2}+3.4 \times 10^{-3} \theta+1.14, \\
f_{l}^{\prime} & =-10^{-4} L+1.11, \\
f_{\xi}^{\prime} & =\xi^{-0.12} .
\end{aligned}
$$

After determination of the above feature points, the simplified model of $N-M$ resistance correlation curves is determined and illustrated with the following formulas.

$$
\begin{gathered}
N \geq N_{c}: \frac{N-N_{c}}{\phi N_{z}-N_{c}}+\frac{M}{M_{c}} \leq 1, \\
N<N_{c}: \frac{N}{N_{c}}+\frac{M-M_{c}}{M_{0}^{\prime}-M_{c}} \leq 1 .
\end{gathered}
$$




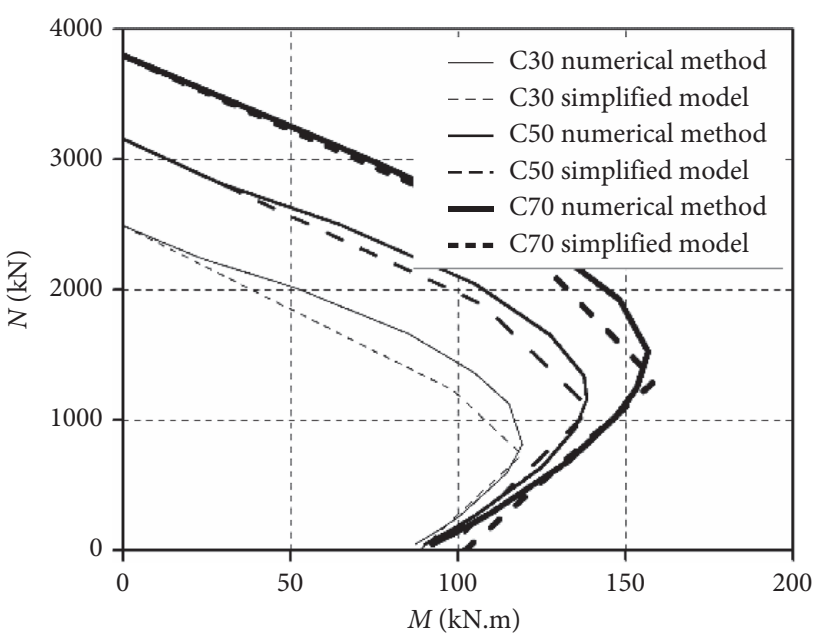

(a)

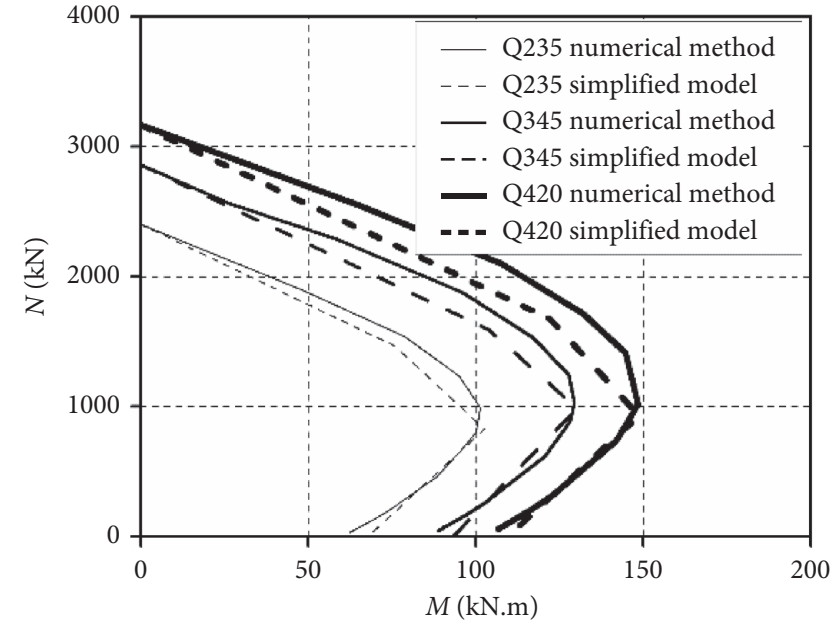

(b)

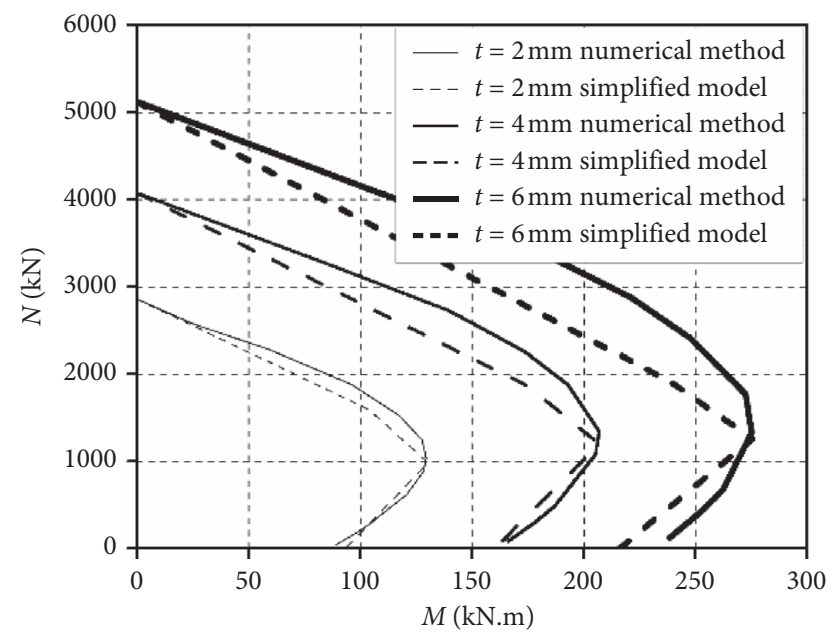

(c)

Figure 21: Verification of cross-sectional simplified $N-M$ resistance model. (a) Concrete strength $(f)_{\mathrm{ck}}$. (b) Steel yield strength $(f)_{\mathrm{y}}$. (c) Steel tube thickness $(t)$.

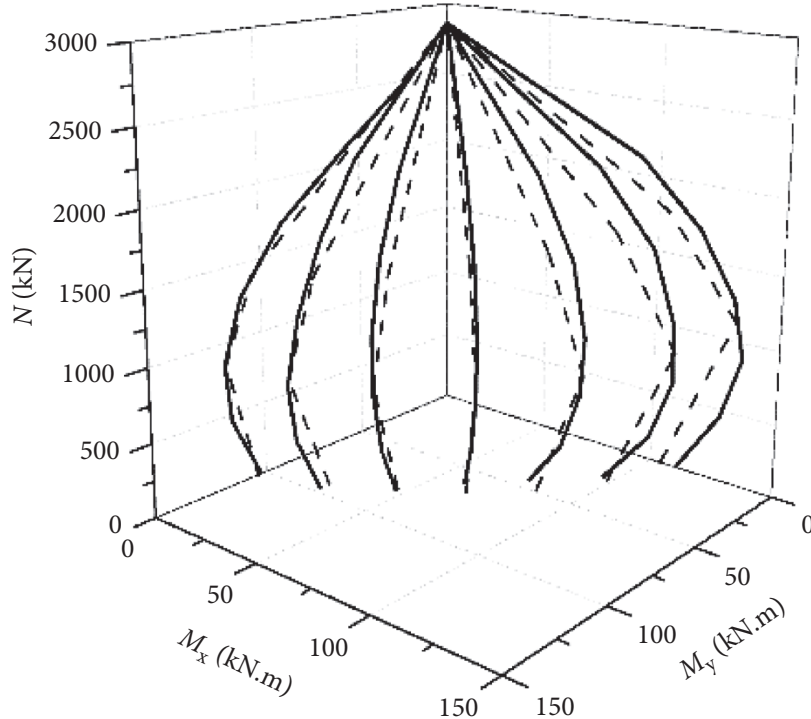

(a)

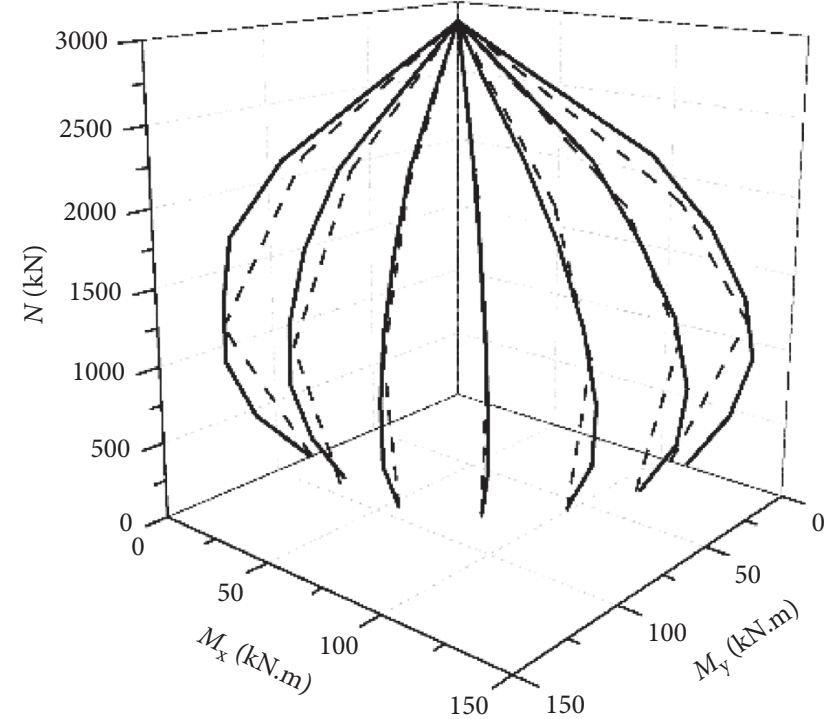

(b)

Figure 22: Verification of cross-sectional simplified $N-M$ resistance model in loading angle $\left(-90^{\circ}-90^{\circ}\right)$. (a) Positive loading $\left(0-90^{\circ}\right)$. (b) Negative loading $\left(-90^{\circ} \sim 0\right)$. 


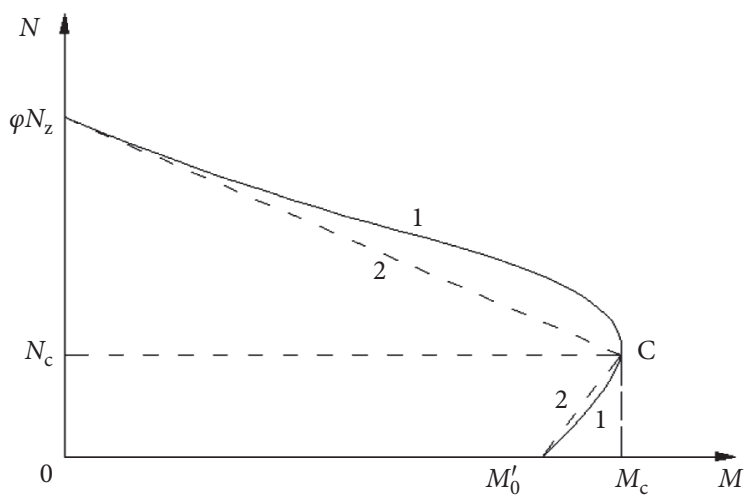

Figure 23: Simplified model of $N-M$ resistance correlation curves of columns.

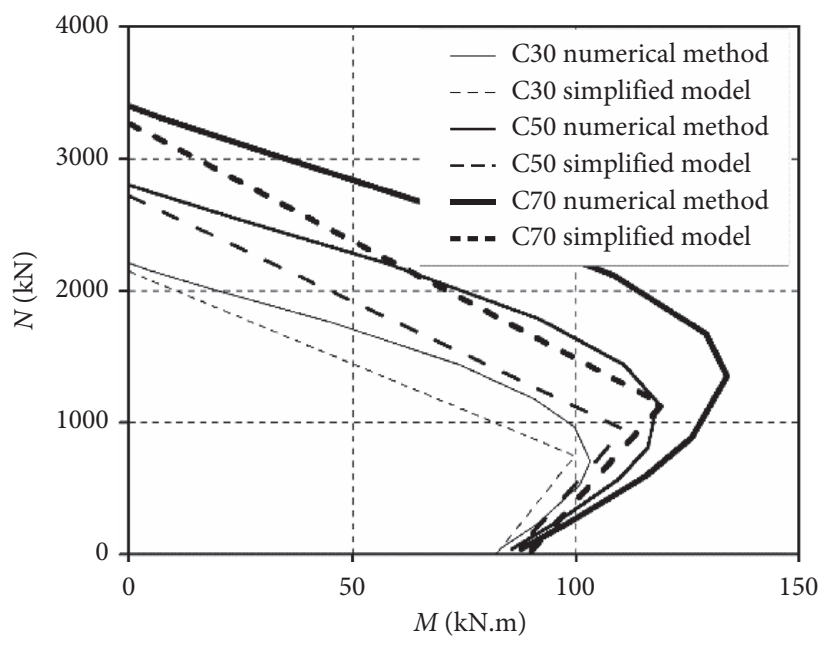

(a)

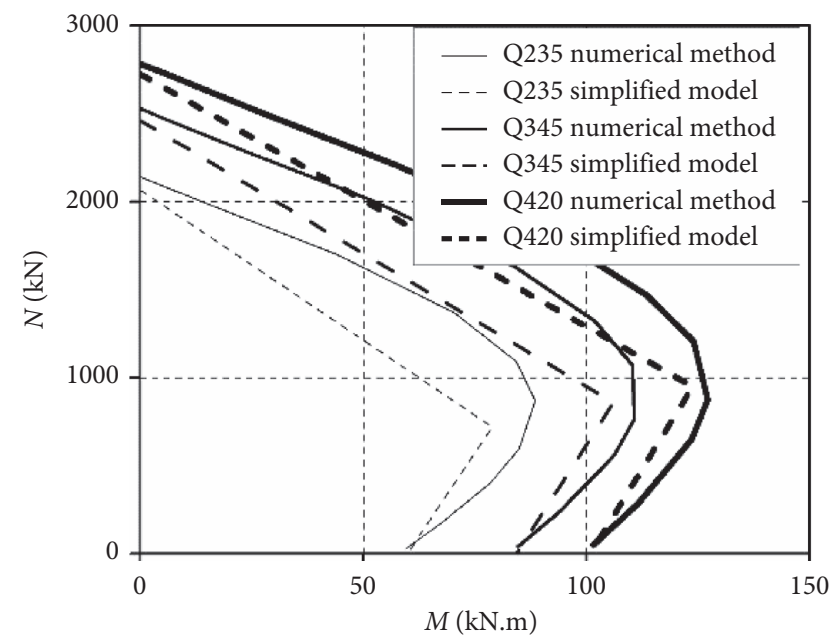

(b)

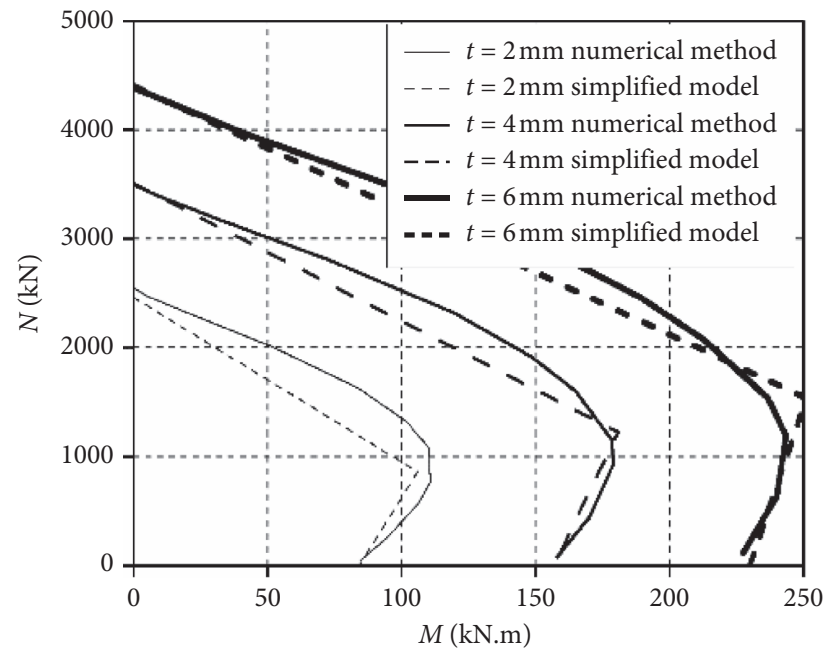

(c)

Figure 24: Verification of simplified N-M resistance model of columns. (a) Concrete strength $(f)_{\mathrm{ck}}$. (b) Steel yield strength $(f)_{y}$. (c) Steel tube thickness $(t)$.

The simplified resistance model is applied to conduct parametric analysis and verified with numerical results. The parameters include concrete strength $f_{\mathrm{ck}}(\mathrm{C} 30, \mathrm{C} 50$, and
C70), steel yielding strength $f_{\mathrm{y}}(\mathrm{Q} 235, \mathrm{Q} 345$, and Q420), steel tube thickness $t(2 \mathrm{~mm}, 4 \mathrm{~mm}$, and $6 \mathrm{~mm})$, slenderness ratio $\lambda$ (13.3 and 60), and loading angle $\theta\left(-90^{\circ}-90^{\circ}\right)$. 


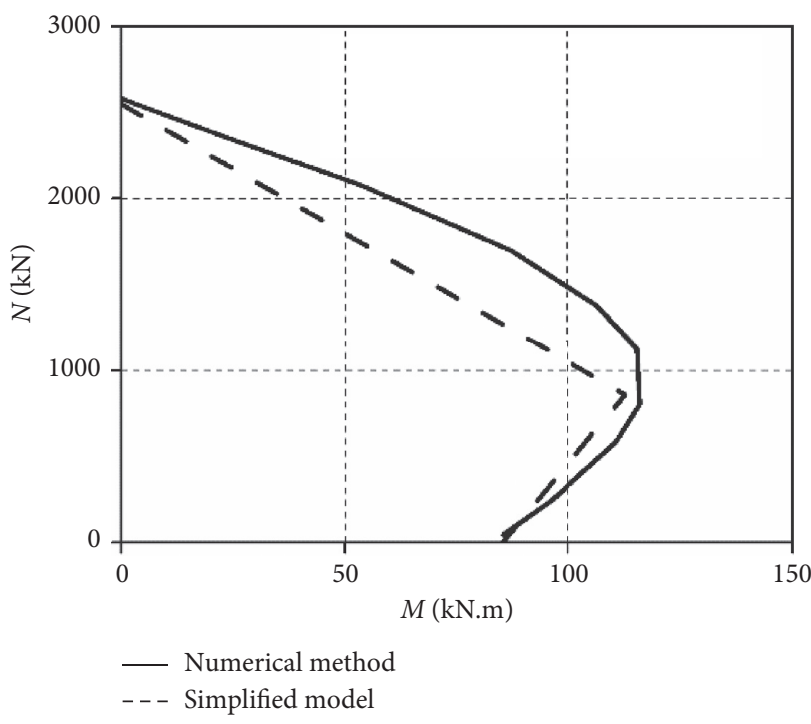

(a)

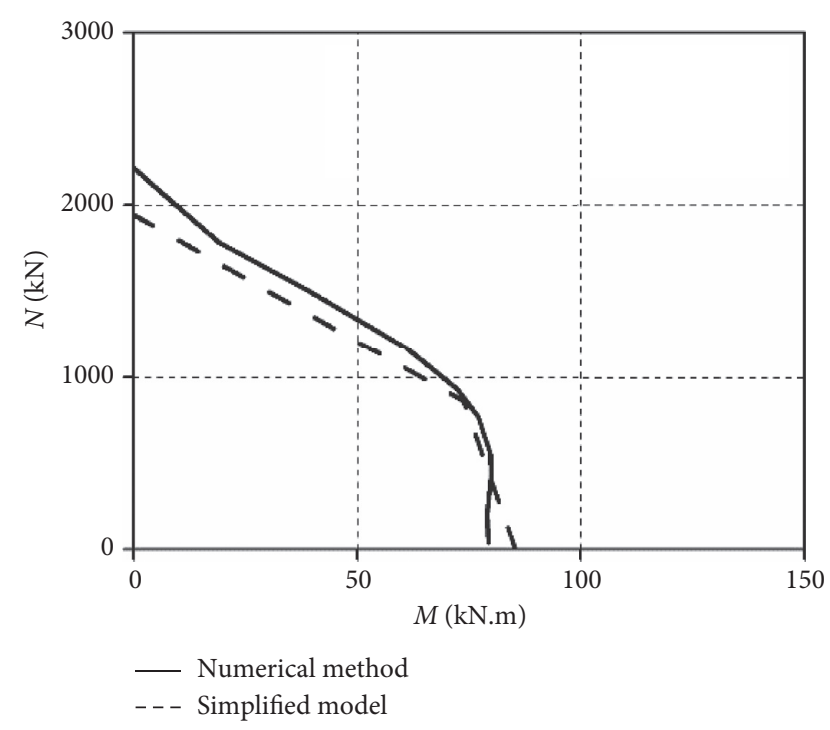

(b)

Figure 25: Verification of simplified $N-M$ resistance model of columns under different slenderness ratios. (a) $\lambda=13.3$. (b) $\lambda=60$.

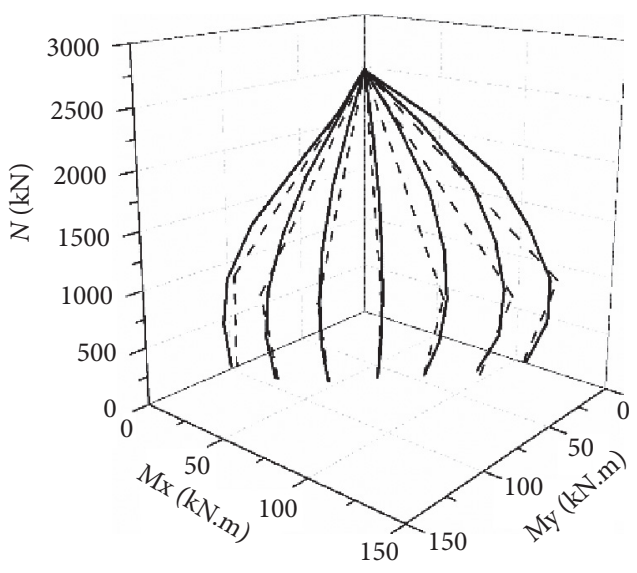

(a)

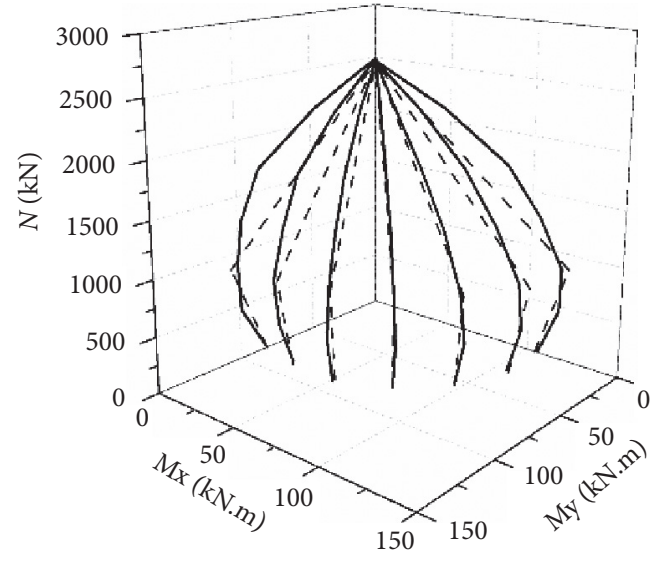

(b)

Figure 26: Verification of simplified $N-M$ resistance model of columns in different loading angles $\left(-90^{\circ}-90^{\circ}\right)$. (a) Positive loading $\left(0-90^{\circ}\right)$. (b) Negative loading $\left(-90^{\circ} \sim 0\right)$.

Figure 24 compares the $N-M$ resistance correlation curves of simplified resistance model (represented by the dotted lines) and numerical program (represented by the continuous lines) in a loading angle of $45^{\circ}$. The simplified resistance model has adequate agreement with the numerical results. The correlation curve of simplified resistance model is enveloped by the corresponding numerical correlation curve, which reveals that the simplified model is a little conservative and can be adopted to predict the static behavior of T-shaped stiffened CFST columns subjected to eccentrically compressive load.

Figure 25 compares the $N-M$ resistance correlation curves of simplified resistance model (represented by the dotted lines) and numerical method (represented by the continuous lines) under different slenderness ratios $\lambda$ $\left(\lambda=13.3\right.$ and 60) in a loading angle of $45^{\circ}$. The simplified resistance model has adequate agreement with the numerical results. The correlation curve of simplified resistance model is almost completely enveloped by corresponding numerical correlation curve, which reveals that the simplified model is a little conservative and can be adopted to predict the static behavior of T-shaped stiffened CFST columns under different slenderness ratios $\lambda$.

Figure 26 compares the $N-M$ resistance correlation curves of simplified resistance model (represented by the dotted lines) and numerical method (represented by the continuous lines) in positive loading angles $\left(0-90^{\circ}\right)$ and negative loading angles $\left(-90^{\circ}-0\right)$. The simplified resistance model has adequate agreement with the numerical results. The correlation curve of simplified resistance model is 
almost completely enveloped by the corresponding numerical correlation curve, which reveals that the simplified model is a little conservative.

\section{Conclusions}

(1) The numerical programs of eccentrically compressive T-shaped stiffened CFST columns proposed in this paper are reasonable and reliable, which are in good agreement with the experimental results.

(2) Parametric analysis of eccentrically compressive T-shaped stiffened CFST columns shows that the peak resistance increases first and then decreases with the increase in the axial compression ratio $n$; the resistance increases with the increase of concrete strength $f_{\mathrm{ck}}$, steel yielding strength $f_{y}$, and steel tube thickness $t$; the resistance increases with the decrease in slenderness ratio $\lambda$.

(3) The design formulas for calculating sectional bearing capacity of T-shaped CFST columns are proposed. The constraint effect of steel tube for concrete is considered in the formulas. The calculated sectional bearing capacities are in good agreement with the numerical program results.

(4) The simplified resistance models of eccentrically compressive T-shaped stiffened CFST section and column proposed in this paper agree well with the numerical results and can be used to predict the mechanical behavior of T-shaped stiffened CFST section and column.

\section{Data Availability}

All the data generated or analyzed during this study are included in this article.

\section{Conflicts of Interest}

The authors declare that they have no conflicts of interest.

\section{Acknowledgments}

This research was supported by Foundation of Key Laboratory of Structures Dynamic Behavior and Control (Ministry of Education) in Harbin Institute of Technology (Grant no. 30620180333), National Natural Science Foundation of China (Grant no. 51878098), National Key Research and Development Program of China (Grant nos. 2016YFC0701201 and 2017YFC0703805), Natural Science Foundation Project of CQ CSTC (cstc2019jcyjmsxmX0580), and Liaoning Provincial Science and Technology Department Project (Grant no. 20180550496).

\section{References}

[1] J. Marin, "Design aids for L-shaped reinforced concrete columns," Journal of the American Concrete Institute, vol. 76, no. 11, pp. 1197-1216, 1979.
[2] C. T. Hsu, "T-shaped reinforced concrete members under biaxial bending and axial compression," Aci Structural Journal, vol. 86, no. 4, pp. 460-468, 1989.

[3] Mallikarjuna and P. Mahadevappa, "Computer aided analysis of reinforced concrete columns subjected to axial compression and bending-I L-shaped sections," Computers \& Structures, vol. 44, no. 5, pp. 1121-1138, 1992.

[4] Mallikarjuna and P. Mahadevappa, "Computer-aided analysis of reinforced concrete columns subjected to axial compression and bending. Part II: T-shaped sections," Computers \& Structures, vol. 53, no. 6, pp. 1317-1356, 1994.

[5] C. Dundar and B. Sahin, "Arbitrarily shaped reinforced concrete members subject to biaxial bending and axial load," Computers \& Structures, vol. 49, no. 4, pp. 643-662, 1993.

[6] C. Y. Yau, S. L. Chan, and A. K. W. So, "Biaxial bending design of arbitrarily shaped reinforced concrete column," Aci Structural Journal, vol. 90, no. 3, pp. 269-278, 1993.

[7] J. Jiao, Y. Ye, and B. Diao, "Bearing capacity analysis of reinforced concrete L-shaped cross-section under biaxial eccentric compression*," Progress in Natural Science, vol. 13, no. 6, pp. 429-433, 2003.

[8] Z. G. Guan, C. K. Huang, D. Wang, and W. L. Shi, "Highly efficient algorithm for calculating load-bearing capacity of special-shaped RC columns under axial compression and biaxial bending," Engineering Mechanics, vol. 23, no. 4, pp. 134-138, 2006.

[9] D. X. Gao, J. Ke, and L. H. Wang, "Seismic behavior analysis of special-shaped column frame structure," Journal of Xian University of Technology, vol. 21, no. 3, pp. 285-288, 2005, in Chinese.

[10] T. C. Wang, X. H. Li, T. Z. Wang, and G. Y. Kang, "Hysteretic behavior of frame with specially shaped columns subjected to cyclic loading," Journal of Jilin University Engineering \& Technology Edition, vol. 37, no. 1, pp. 224-228, 2007, in Chinese.

[11] D. Wang and X. L. Lv, "Experimental study on seismic behavior of concrete-filled steel T-section and L-section columns," Journal of Building Structures, vol. 26, no. 4, pp. 39-44, 2005, in Chinese.

[12] Z. Y. Lin, Z. Y. Shen, and J. H. Luo, "Hysteretic behavior of concrete-filled L-section steel tubular columns under cyclic loading," Progress in Steel Building Structures, vol. 11, no. 2, pp. 12-17, 2009, in Chinese.

[13] J. C. Zhang, Z. Y. Shen, Z. Y. Lin, and J. H. Luo, "Experimental research on seismic behavior of concrete-filled L-shaped steel tubular frames," Journal of Building Structures, vol. 31, no. 8, pp. 1-7, 2010, in Chinese.

[14] T. Zhou, Z. Chen, and H. Liu, "Seismic behavior of special shaped column composed of concrete filled steel tubes," Journal of Constructional Steel Research, vol. 75, no. 75, pp. 131-141, 2012.

[15] X. Liu, C. Xu, J. Liu, and Y. Yang, "Research on special-shaped concrete-filled steel tubular columns under axial compression," Journal of Constructional Steel Research, vol. 147, pp. 203-223, 2018.

[16] G. F. Du, J. Zhang, Y. Li, J. C. Zhang, and L. Zeng, "Experimental study on hysteretic model for L-shaped concrete-filled steel tubular column subjected to cyclic loading," Thin-Walled Structures, vol. 144, 2019.

[17] I. Valente and P. J. S. Cruz, "Experimental analysis of Perfobond shear connection between steel and lightweight concrete," Journal of Constructional Steel Research, vol. 60, no. 3-5, pp. 465-479, 2004.

[18] W. Lorenc, M. Kożuch, and S. Rowiński, "The behaviour of puzzle-shaped composite dowels - Part I: Experimental 
study," Journal of Constructional Steel Research, vol. 101, pp. 482-499, 2014.

[19] M. Classen and J. Hegger, "Assessing the pry-out resistance of open rib shear connectors in cracked concrete - Engineering model with aggregate interlock," Engineering Structures, vol. 148, pp. 254-262, 2017.

[20] S. P. Schneider, "Axially loaded concrete-filled steel tubes," Journal of Structural Engineering, vol. 124, no. 10, pp. 11251138, 1998.

[21] K. Sakino, H. Nakahara, S. Morino, and I. Nishiyama, "Behavior of centrally loaded concrete-filled steel-tube short columns," Journal of Structural Engineering, vol. 130, no. 2, pp. 180-188, 2004.

[22] Z. Tao, L.-H. Han, and D.-Y. Wang, "Experimental behaviour of concrete-filled stiffened thin-walled steel tubular columns," Thin-Walled Structures, vol. 45, no. 5, pp. 517-527, 2007.

[23] X. Z. Zang, Y. L. Yang, and C. Z. Xu, "Research on hysteretic performance of stiffened T-shaped steel tube confined concrete column," Earthquake Engineering and Engineering Vibration, vol. 37, no. 05, pp. 129-138, 2017, in Chinese.

[24] Z.-L. Zuo, J. Cai, C. Yang, Q.-J. Chen, and G. Sun, "Axial load behavior of L-shaped CFT stub columns with binding bars," Engineering Structures, vol. 37, no. 5, pp. 88-98, 2012a.

[25] Z.-L. Zuo, J. Cai, C. Yang, and Q.-J. Chen, "Eccentric load behavior of L-shaped CFT stub columns with binding bars," Journal of Constructional Steel Research, vol. 72, pp. 105-118, $2012 b$.

[26] Y. Yang, Y. Wang, F. Fu, and J. Liu, "Static behavior of T-shaped concrete-filled steel tubular columns subjected to concentric and eccentric compressive loads," Thin-Walled Structures, vol. 95, pp. 374-388, 2015.

[27] C. Z. Xu, Y. L. Yang, X. Tang, and J. P. Liu, "experimental research on static behavior of stiffened T-shaped concretefilled steel tubular stubs subjected to concentric axial loading," International Journal of Steel Structures, vol. 19, pp. 591-602, 2019.

[28] G. F. Du, L. H. Xu, H. R. Xu, and F. Wen, “Test study on behavior of T-shaped concrete filled steel tubular short columns under axial compression," Journal of Xian University of Architecture \& Technology, vol. 25, no. 3, pp. 188-194, 2008, in Chinese.

[29] Y. Yang, H. Yang, and S. Zhang, "Compressive behavior of T-shaped concrete filled steel tubular columns," International Journal of Steel Structures, vol. 10, no. 4, pp. 419-430, 2010.

[30] Y. Sui, Y. Tu, Q. Guo, J. Zhang, and F. Ke, "Study on the behavior of multi-cell composite T-shaped concrete-filled steel tubular columns subjected to compression under biaxial eccentricity," Journal of Constructional Steel Research, vol. 159, pp. 215-230, 2019.

[31] L. H. Han, Concrete-filled Steel Tubular Structures - Theory and Practice, Science Press, Beijing, China, 2007, in Chinese. 